\title{
New Tech v. New Deal: Fintech as a Systemic Phenomenon
}

\author{
Saule T. Omarova ${ }^{\dagger}$
}

Fintech is the hottest topic in finance today. Recent advances in cryptography, data analytics, and machine learning are visibly "disrupting" traditional methods of delivering financial services and conducting financial transactions. Less visibly, fintech is also changing the way we think about finance: it is gradually recasting our collective understanding of the financial system in normatively neutral terms of applied information science. By making financial transactions easier, faster, and cheaper, fintech seems to promise a micro-level "win-win" solution to the financial system's many ills.

This Article challenges such narratives and presents an alternative account of fintech as a systemic, macro-level phenomenon. Grounding the analysis of evolving fintech trends in a broader institutional context, the Article exposes the normative and political significance of fintech as the catalyst for a potentially decisive shift in the underlying public-private balance of powers, competencies, and roles in the financial system. In developing this argument, the Article makes three principal scholarly contributions. First, it introduces the concept of the New Deal settlement in finance: a fundamental political arrangement, in force for nearly a century, pursuant to which profit-seeking private actors retain control over allocating capital and generating financial risks, while the sovereign public bears responsibility for maintaining systemic financial stability. Second, the Article advances a novel conceptual framework for understanding the deep-seated dynamics that have eroded the New Deal settlement in recent decades. It offers a taxonomy of core mechanisms that both (a) enable private actors to continuously synthesize tradable financial assets and scale up trading activities, and (b) undermine the public's ability to manage the resulting system-wide risks. Finally, the Article shows how and why specific fintech applications - cryptocurrencies, distributed ledger technologies, digital crowdfunding, and robo-advising - are poised to amplify the effect of these destabilizing mechanisms, and thus potentially exacerbate the tensions and imbalances in today's financial markets and the broader economy. It is this potential that renders fintech a public policy challenge of the highest order.

${ }^{\dagger}$ Beth and Marc Goldberg Professor of Law, Cornell University. For thoughtful comments and criticisms, I thank participants at conferences and workshops at Vanderbilt Law School, Oxford University, the University of Texas Law School, the Baldy Center for Law and Social Policy at SUNYBuffalo, and the University of Pennsylvania Law School. Special thanks to my colleague and frequent collaborator, Bob Hockett. All errors are mine. 


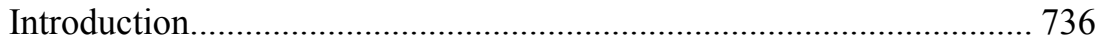

I. Fintech as a Challenge to the New Deal Settlement............................ 743

A. Fintech: A Preliminary Overview ....................................... 743

B. The New Deal Settlement in the Financial Sector.................. 746

C. Pre-Fintech Erosion of the New Deal Settlement:

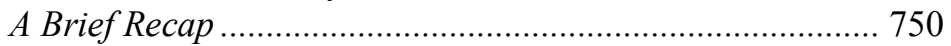

D. Fintech and the New Deal Settlement: Reframing the Inquiry

II. The Logic of Financial Innovation and the Erosion of the New Deal 756

A. Focusing the Inquiry: Secondary Markets in Financial

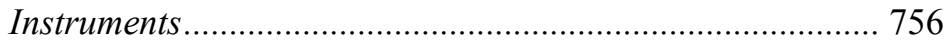

B. The Mechanisms of Secondary Market Proliferation: A Preliminary Taxonomy.

1. The Market's Modus Operandi: Synthesizing and Scaling Up 760

2. The Four Mechanisms of Synthesizing Assets and Scaling Up Trading Activity...................................................... 762

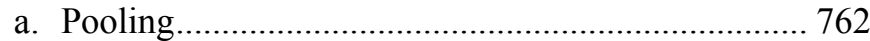

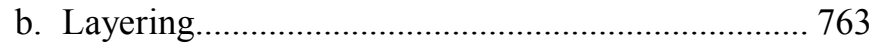

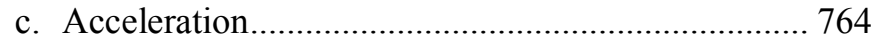

d. Compression............................................................ 765

C. Systemic Implications of Secondary Market Proliferation .... 767

III. Decoding Fintech: Technological Revolution, Market Evolution, or

Power Devolution? 770

A. Eliminating Frictions: Cryptocurrencies and Distributed

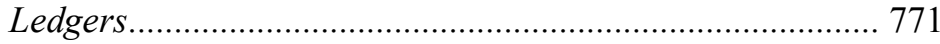

1. Bitcoin: Synthesizing Assets........................................... 771

2. Distributed Ledger Technology: Scaling Up Trading.... 775

B. Democratizing Finance: Digital Crowdfunding and Robo-

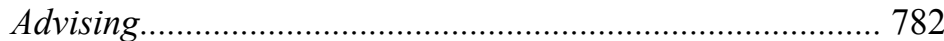

1. Marketplace Lending and ICOs: Synthesizing Assets... 782

2. Robo-Advising: Scaling Up Trading ............................. 787

C. Fintech as a Systemic Phenomenon: Unsettling the Public-

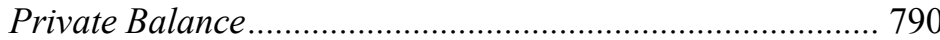

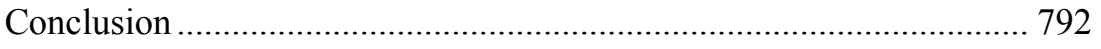

Introduction

"Fintech," a popular term referring to the wide universe of innovative technology-enabled financial services, is by far the hottest topic in today's 
finance. ${ }^{1}$ Fintech is visibly changing the way we conduct financial transactions and use financial services: volatile cryptocurrencies are becoming a mainstream trading asset, companies are raising capital by issuing digital tokens instead of securities, and robots are advising people on some of the most important financial decisions of their lives. ${ }^{2}$ Less visibly, however, fintech is also beginning to change the way we think about finance. Increasingly ubiquitous, the fintech phenomenon is gradually reframing our understanding of the financial system in seemingly objective, science-driven terms, as yet another sphere of targeted application of information technologies and computer analytics.

This emerging narrative of finance is seductive in its simplifying elegance. It focuses on concrete transactional aspects of finance, rather than its inherently complex systemic dynamics. Targeting solutions for identified and isolated frictions in financial market transactions, fintech embodies an inherently microrather than macro-level view of the financial system. It deals with clearly functionally defined, programmable (and thus controllable) business processes and tools, rather than difficult normative judgments and policy tradeoffs. Yet, the fintech narrative also has distinct undertones of a social revolution in its broader aspirations to rebuild financial markets on principles of mutuality, cooperation, and inclusiveness. In that sense, its implicit promise is to redefine not only how we transact with one another, but also who we are as a community: new technology will succeed where old politics failed. ${ }^{3}$

What should we make of this emerging narrative? Does fintech signify a genuine revolutionary shift in the fundamental dynamics of finance? And, if so, what are the nature and potential implications of this fintech revolution? Is it capable of delivering the ultimate-normatively neutral and politically uncontestable - cure for the financial system's underlying dysfunctions?

1. See, e.g., Garrett Baldwin, The Top 10 Trends in Fintech, FUTURES (Apr. 15, 2016), http://www.futuresmag.com/2016/04/15/top-10-trends-fintech [https://perma.cc/FV97-LCVR] ("No term is more ubiquitous in today's financial media than fintech."); Daniel Newman, Top 5 Digital Transformation Trends in Financial Services, FORBES (May 9, 2017), https://www.forbes.com/sites/danielnewman/2017/05/09/top-5-digital-transformation-trends-infinancial-services/\#75cd2c1e204c [https://perma.cc/HD3Z-JZ4A] ("If it feels like this change is fast and furious, you're right."); Bob Pisani, Here's Where Fintech Is Heading Next, CNBC (June 6, 2016), https://www.cnbc.com/2016/06/06/heres-where-fintech-is-heading-next.html [https://perma.cc/VEU76BUQ] ("The interaction between finance and technology, or 'fintech,' remains a hot topic.").

2. For example, in 2017, an influential industry report identified seventeen distinct "fintech services" offered by a wide array of providers in such areas as "money transfer and payments, financial planning, savings and investment, borrowing, and insurance." ERNST \& YOUNG, EY FINTECH ADOPTION INDEX 2017: THE RAPID EMERGENCE OF FINTECH 6, http://www.ey.com/Publication/vwLUAssets/ey-fintech-adoption-index-2017/\$FILE/ey-fintechadoption-index-2017.pdf [https://perma.cc/RQ39-L5VV].

3. See, e.g., Avi Salzman, Blockchain Is Starting to Show Real Promise Amid the Hype, BARRON's (Aug. 17, 2018), https://www.barrons.com/articles/blockchain-is-starting-to-show-realpromise-amid-the-hype-1534554901 [https://perma.cc/PB3L-BB7J] (quoting an industry insider's definition of blockchain as "a technological solution to a political problem"). 
The purpose of this Article is not to provide definitive answers to these questions. Rather, it is to propose a general conceptual framework within which they should be addressed. Much has already been, and continues to be, written about the rise of fintech and its growing impact on financial markets and regulation. ${ }^{4}$ Legal scholars, in particular, are increasingly interested in various legal and regulatory challenges posed by the new technological advances in finance. ${ }^{5}$ Some of the most valuable insights to date have come from the literature examining specific legal, economic, or operational aspects of individual fintech applications. ${ }^{6}$ Alongside these targeted legal analyses, there is a rapidly expanding body of scholarship that attempts to take a broader inventory of issues fintech raises for lawmakers and financial regulators. ${ }^{7}$ This literature

4. For a small sample of recent high-profile reports and studies, see FIN. STABILITY BD., FINANCIAL STABILITY IMPLICATIONS FROM FINTECH (June 27, 2017), http://www.fsb.org/wpcontent/uploads/R270617.pdf [https://perma.cc/QG98-EUH3]; Fin. STABILITY BD., FinTECH CREDIT: Market Structure, Business Models AND FinanCial Stability IMPLiCATIONS (May 22, 2017), http://www.fsb.org/wp-content/uploads/CGFS-FSB-Report-on-FinTech-Credit.pdf [https://perma.cc/5DUJ-YWSG]; U.K. CRYPTOASSETS TASKFORCE, FinAL REPORT (Oct. 2018), https://assets.publishing.service.gov.uk/government/uploads/system/uploads/attachment_data/file/75207 0/cryptoassets_taskforce_final_report_final_web.pdf [https://perma.cc/E485-3P5Y]; U.S.S. DEP'T OF THE Treasury, Report to President TRUMP: A Financial System That CREATES ECONOMiC OPPORTUNITIES: NONBANK FINANCIALS, FINTECH, AND INNOVATION (July 2018), https://home.treasury.gov/sites/default/files/2018-07/A-Financial-System-that-Creates-EconomicOpportunities---Nonbank-Financi....pdf [https://perma.cc/C6PQ-NG4J] [hereinafter TREASURY REPORT]; WORLD ECON. FORUM, REALIZING THE POTENTIAL OF BLOCKCHAIN: A MULTISTAKEHOLDER APPROACH TO THE STEWARDSHIP OF BLOCKCHAIN AND CRYPTOCURRENCIES (June 2017), http://www3.weforum.org/docs/WEF Realizing Potential Blockchain.pdf [https://perma.cc/PGW4J4Y6]; John Schindler, FinTech and Financial Innovation: Drivers and Depth (Fed. Reserve Fin. \& Econ. Discussion Series Paper No. 2017-081, 2017), https://www.federalreserve.gov/econres/feds/files/2017081pap.pdf [https://perma.cc/CS2B-F43J].

5. For a sample of the rapidly growing legal scholarship on these issues, see Douglas W. Arner, Janos Barberis \& Ross P. Buckley, FinTech, RegTech, and Reconceptualization of Financial Regulation, 37 NW. J. INT'L L. \& Bus. 371 (2017); Douglas W. Arner, Janos Barberis \& Ross P. Buckley, The Evolution of Fintech: A New Post-Crisis Paradigm?, 47 GEO. J. INT'L L. 1271 (2016); Chris Brummer \& Yesha Yadav, Fintech and the Innovation Trilemma, 107 GEO. L.J. 235 (2019); Iris H-Y Chiu, Fintech and Disruptive Business Models in Financial Products, Intermediation, and Market-Policy Implications for Financial Regulators, 21 J. TECH. L. \& POL'Y 55 (2016); Rory Van Loo, Making Innovation More Competitive: The Case of Fintech, 65 UCLA L. REV. 232 (2018); William J. Magnuson, Regulating Fintech, 71 VAnD. L. ReV. 1167 (2018); and Dirk A. Zetzsche et al., From FinTech to TechFin: The Regulatory Challenges of Data-Driven Finance (EBI Working Paper Series No. 6, 2017), https://papers.ssrn.com/sol3/papers.cfm?abstract_id=2959925 [https://perma.cc/A69R-923L].

6. See, e.g., John Armour \& Luca Enriques, The Promise and Perils of Crowdfunding: Between Corporate Finance and Consumer Contracts, 81 MoD. L. REV. 51 (2018); Shlomit AzgadTromer, Crypto Securities: On the Risks of Investments in Blockchain-Based Assets and the Dilemmas of Securities Regulation, 68 AM. U. L. REV. 69 (2018); Tom Baker \& Benedict G. C. Dellaert, Regulating Robo Advice Across the Financial Services Industry, 103 IowA L. REV. 713 (2018); Adam J. Levitin, Pandora's Digital Box: The Promise and Perils of Digital Wallets, 166 U. PA. L. REV. (2017); Jeanne Schroeder, Bitcoin and the Uniform Commercial Code, 24 U. MiAmi Bus. L. Rev. 1 (2016); Angela Walch, The Bitcoin Blockchain as Financial Market Infrastructure: A Consideration of Operational Risk, 18 J. Legis. \& PUB. POL’y 837 (2015); Shaanan Cohney et al., Coin-Operated Capitalism, 119 Colum. L. REV. 591 (2019).

7. See sources cited supra note 5. For analyses focusing on financial regulators' attempts to encourage technological innovation and to develop their own technological capabilities, see Rory Van Loo, Rise of the Digital Regulator, 66 DuKE L.J. 1267 (2017); Hilary J. Allen, A US Regulatory 
helpfully identifies certain key considerations the regulators should "keep in mind" as they address such issues in practice and discusses innovative ways for regulators to "stay on top" of technological change. Yet, it stops short of offering a coherent conceptual account of fintech as a systemic phenomenon. As the list of identified regulatory concerns and considerations grows longer and more detailed, however, the need for an overarching conceptual framework within which to analyze the role of technology in finance becomes increasingly pressing. ${ }^{8}$

Aiming to fill this gap in the existing literature, this Article takes a deeper and more encompassing systemic view of fintech, both as a financial market phenomenon and as a regulatory challenge. It takes a position that, in order to make real sense of technological changes "disrupting" today's financial markets and regulations, it is necessary to broaden the analytical and normative lens beyond the immediate economic and legal effects of specific fintech applications. At bottom, an inquiry into the nature and dynamics of the "fintech revolution" is, and should be, an integral part of the broader inquiry into the nature and dynamics of finance itself. The latter, in turn, is, and should be, a fundamentally normative inquiry into the social function-and, by extension, dysfunction - of modern finance. Therefore, the Article posits, the role of technology in finance cannot be properly assessed, or even understood, without explicitly addressing the underlying questions about the role of today's finance in the broader socio-economic system.

The emerging fintech narrative in its present form, however, tends to mask this underlying continuity. The newly empowered and fashionable notion of "finance as technology" is threatening to eclipse that of "finance as public policy." This Article seeks to reintegrate these two concepts, both as a matter of descriptive accuracy and as a normative matter. Technology enables and drives financial transactions, but so does public policy embodied in financial laws and regulations. On a micro-level, finance often appears primarily, if not purely, transactional: a matter of individualized private exchange among market actors. On a macro-level, however, modern finance is a matter not only of great public importance but also of great public involvement. ${ }^{9}$ The rise of fintech throws into

Sandbox? (Working Paper, 2018), https://papers.ssrn.com/sol3/papers.cfm?abstract id=3056993 [https://perma.cc/5VUE-QXNQ]. A somewhat distinct thread in this literature focuses more narrowly on fintech-related changes in the familiar patterns of transactional "intermediation" in various contexts. See Benjamin Geva, Disintermediating Electronic Payments: Digital Cash and Virtual Currencies, 31 J. INT'L BANKING L. \& Reg. 661 (2017); Kathryn Judge, The Future of Direct Finance: The Diverging Paths of Peer-to-Peer Lending and Kickstarter, 50 WAKE FOREST L. REV. 603 (2015).

8. For a recent review of the emerging economic research on fintech, see Peter Gomber, Jascha-Alexander Koch \& Michael Siering, Digital Finance and Fintech: Current Research and Future Research Directions, 87 J. BUS. ECON. 537 (2017). As this review shows, there are presently significant gaps in the economic literature on the subject.

9. For an in-depth theoretical account of the fundamental hybridity of modern finance as a public-private enterprise, see Robert C. Hockett \& Saule T. Omarova, The Finance Franchise, 102 CORNELL L. REV. 1143 (2017). 
sharp relief this essential hybridity of modern finance and exposes some of the deepest normative tensions underlying it.

The Article argues that, from this systemic perspective, the fintech phenomenon has a broader significance than a "disruption" in the prevailing modes of, or institutional channels for, delivery of specific financial services. Its arrival marks a potentially decisive shift in the fundamental political arrangement underlying the operation of the modern financial system, as it currently exists in most advanced markets. Not surprisingly, that arrangement is most easily discernable in the United States, which, for the better part of the last hundred years or so, has been the world's leader in developing not only largescale capital markets but also the sophisticated legal and regulatory apparatus for a sustained and systematic oversight of financial markets and institutions. The U.S. system of financial sector regulation took shape during the New Deal era, as part of a concerted government response to the economic and political fallout from the stock market crash of 1929 and the Great Depression that followed it. ${ }^{10}$ Today's elaborate scheme of U.S. financial regulation and supervision, directly or indirectly replicated around the world, continues to rest on the fundamental norms and policy principles at the core of the New Deal reforms. ${ }^{11}$ These deep underlying norms and principles form what this Article calls the "New Deal settlement" in the sphere of finance. ${ }^{12}$

As discussed below, the New Deal settlement in finance reflects certain politically derived judgments about the optimal balance of private freedom and public control in the financial market. ${ }^{13}$ Under this paradigm, private market actors retain control over substantive decisions on how to allocate financial capital to various productive uses - and thus the power to determine the overall volume and structure of financial claims in the system. The public, on the other hand, bears the primary responsibility for maintaining the overall stability of the financial system and enabling markets to function smoothly and efficiently. Government regulation is the indispensable mechanism through which the public manages the moral hazard built into this arrangement: in essence, regulation constrains market participants' ability to generate excessive system-wide risks in pursuit of private profits. ${ }^{14}$

10. See Saule T. Omarova, One Step Forward, Two Steps Back? The Institutional Structure of U.S. Financial Services Regulation After the Crisis of 2008, in INSTITUTIONAL STRUCTURE OF FINANCIAL REgUlation: THEORIES AND INTERNATIONAL EXPERIENCES 137 (Robin Hui Huang \& Dirk Schoenmaker eds., 2014) (detailing the institutional legacy of the New Deal in the financial sector). 11. See Saule T. Omarova, The Dodd-Frank Act: A New Deal for a New Age?, 15 N.C. BANKING INST. 83 (2011) (analyzing the key elements of the regulatory philosophy in the financial sector).

12. For the ease of reference, the Article uses this term in a shortened form as simply the "New Deal settlement." That term, however, refers exclusively to the fundamental pattern of division of public and private powers and responsibilities in the sphere of finance and not in any other context.

13. For a discussion of the New Deal settlement's core features, see infra Section I.B.

14. See id. 
The inherently unstable and contestable nature of this balance is the source of the fundamental tension at the core of the New Deal settlement. In an important sense, the entire history of U.S. financial markets and regulation since the New Deal era has been the history of continuous renegotiation and readjustment of this public-private boundary, driven by private market actors' continuous efforts to expand their freedom to create and trade financial claims. ${ }^{15}$

To elucidate these deep-seated systemic dynamics, the Article deliberately shifts the analytical focus from primary markets, in which firms raise capital by issuing financial claims, to secondary markets in which such claims trade. Despite legislators' and regulators' continuing preoccupation with 'capital formation" in primary markets, the financial system's center of gravity has long since shifted to secondary markets. ${ }^{16}$ Secondary markets in financial assets currently dwarf primary markets in terms of size, complexity, and systemic significance. ${ }^{17}$ Secondary markets also operate as the principal sites of relentless financial "innovation" and chronic over-generation of systemic risk. ${ }^{18}$ The key to understanding what drives today's complex financial system, therefore, is to understand what drives the continuous growth and proliferation of secondary markets.

Operationalizing this insight, the Article identifies the core mechanisms and techniques that enable private actors to create and grow-continuously and virtually unconstrained - secondary markets for financial risk trading. It argues that the growth of financial markets is best understood by reference to two interrelated system-wide transactional practices: (1) continuous synthesizing of new tradable financial assets and (2) scaling up the volume and velocity of trading activity in financial markets. The Article breaks down these phenomena further by showing how private market actors pursue these overarching objectives via four principal mechanisms: pooling and layering of claims, and acceleration and compression of trades. ${ }^{19}$

System-wide deployment of these transaction meta-technologies - pooling, layering, acceleration, and compression - enables the constant growth and complexification of the financial market. By the same token, it magnifies the extent and urgency of the public's obligation to accommodate privately created claims and to manage macro-financial risks. Critically, however, the public side is not always able to keep up with these increased demands by expanding its regulatory oversight capabilities. In fact, private actors' very success in synthesizing financial assets and scaling up trading activities often depends on

15. It is important to emphasize from the outset, however, that this Article does not purport to present a historical analysis of the New Deal, its intellectual or political origins, or any of its specific institutional accomplishments.

16. See infra Section II.A.

17. See infra notes 94-96 and accompanying text.

18. Id.

19. See infra Section II.B.2. 
the lack or inefficacy of regulatory controls - a familiar story aptly illustrated by financial market developments since the early 1980s and the global financial crisis these developments brought about. ${ }^{20}$

This Article examines the rise of fintech in the context of this decades-long process of gradual erosion of the New Deal settlement in finance. It posits that deciphering the meaning of "fintech revolution" as a macro-financial, systemic phenomenon requires a deeper understanding of how specific fintech applications impact the public's capacity to maintain the stability of the macroenvironment. Fintech may present a unique opportunity to correct the increasingly problematic imbalance between private misallocation of credit and the public's ability to modulate credit aggregates, or it may further intensify that imbalance. $^{21}$

Reframing the inquiry along these dimensions, the Article argues that the more established fintech applications to date are already exhibiting signs of skewing the balance further in favor of private actors' unrestrained freedom to generate - and over-generate - financial risk. While it may be too early to draw definitive conclusions, the recent advances in computing power, cryptography, data analytics, and machine learning appear poised to amplify the long-lasting, systemically destabilizing trends in the financial markets. As shown below, new technological tools enable private market participants to engage in the continuous synthesizing of crypto-assets that are (a) effectively untethered from, and thus unconstrained by, any productive activity in the real economy, and (b) tradable in potentially infinitely scalable virtual markets. What is commonly seen as the key micro-level advantage of fintech - its ability to eliminate transactional "frictions" and to circumvent traditional market boundaries-also operates to amplify the system's capacity to fuel financial speculation on an unprecedented scale. ${ }^{22}$ On a macro-level, therefore, the key risk posed by fintech lies in its (still not fully known) potential to exacerbate the financial system's dysfunctional tendency toward unsustainably self-referential growth. ${ }^{23}$

From this perspective, the onset of the fintech era marks a crucial political moment. Invisibly, the new technology is "disrupting" the New Deal settlement in finance. The nearly century-old arrangement that rigidly separated credit generation and allocation (an exclusively private right) from credit modulation and accommodation (an explicitly public responsibility) appears increasingly illsuited for ensuring systemic stability in the emergent world of frictionless crypto-speculation. ${ }^{24}$ Accordingly, in trying to make sense of specific

20. See infra Section I.C.

21. See Hockett \& Omarova, supra note 9. For a detailed post-crisis account of the importance of structural, as opposed to individual or firm-level, incentives for financial risk-taking, see Robert C. Hockett, A Fixer-Upper for Finance, 87 WASH. U. L. REV. 1213 (2010).

22. For a detailed discussion, see infra Part III.

23. See infra Section III.C.

24. Id. 
technological advances, we must not lose sight of the ultimate systemic challenge rising in their background: the growing need to rethink the current public-private boundary in finance. ${ }^{25}$

The Article is organized as follows. Part I provides a brief overview of recent fintech developments and places them in the context of what I call the New Deal settlement in finance. It outlines the defining features of this political settlement and traces the process of its gradual erosion in recent decades. Delving deeper into this process, Part II advances a novel conceptual framework for understanding the fundamental dynamics of secondary markets in financial instruments. It offers a preliminary taxonomy of the principal mechanisms - or system-level transaction meta-technologies - that enable private market actors to engage in continuous synthesizing of tradable assets and scaling up of trading activities. Finally, Part III examines specific fintech applications-Bitcoin, distributed ledger technology, marketplace lending, initial coin offerings (ICOs), and robo-advising - from the perspective of their potential to amplify the operation of these core financial market mechanisms. It concludes by drawing out some of the key systemic implications of these new technologies and, accordingly, redefining fintech as a public policy challenge of the highest order. ${ }^{26}$

\section{Fintech as a Challenge to the New Deal Settlement}

\section{A. Fintech: A Preliminary Overview}

"Fintech" is an umbrella term that refers to a variety of digital technologies applied to the provision of financial services and, more generally, developments in the financial sector. Perhaps the most immediately recognizable symbol of the fintech era is the rise of private cryptocurrencies, defined generally as "any form of currency that only exists digitally, that usually has no central issuing or regulating authority but instead uses a decentralized system to record transactions and manage the issuance of new units, and that relies on cryptography to prevent counterfeiting and fraudulent transactions. ${ }^{27}$ Bitcoin is

25. For a comprehensive theoretical and normative account of the core public-private dynamics in finance, see Hockett \& Omarova, supra note 9.

26. It is worth noting here that this Article does not explicitly address such familiar and undoubtedly important themes in the current discourse on fintech as, for example, protection of customer data privacy, cybersecurity, application of anti-money laundering rules, or consumer and investor fraud prevention. Nor does it engage in lengthy discussions of potential public benefits of new technologiesincluding potential uses of technology for regulatory compliance and monitoring purposes - that are easy to stipulate in the abstract. Furthermore, because the primary thrust of this Article is analytical and expository, it contains no specific policy recommendations or regulatory proposals. Developing truly effective policy proposals requires a deeper and more systematic analysis of the problem they purport to solve. It is the latter, conceptually prior, task that is at the heart of the present project.

27. Cryptocurrency, MERRIAM-WEBSTER DiCTIONARY, https://www.merriamwebster.com/dictionary/cryptocurrency [https://perma.cc/934D-J3E9]. It is notoriously difficult to draw 
the first cryptocurrency to date that went mainstream, albeit as an investment asset rather than as a viable substitute for fiat money. ${ }^{28}$ The Bitcoin network is built on blockchain technology, which uses a complex algorithm to allow decentralized verification and recording of each transaction in a publicly viewable distributed ledger. ${ }^{29}$

Importantly, blockchain-or, more broadly, distributed ledgertechnology potentially allows for a wider range of uses outside simply supporting specific cryptocurrencies. Thus, Ethereum, a blockchain platform designed to host an unlimited number of project-specific third-party applications, enables what are now known as "smart contracts" to automate the execution of a wide variety of transactions, including the ongoing performance of transacting parties' obligations. ${ }^{30}$ Among other things, "smart contract" algorithms can automatically disburse payments or transfer title to assets upon the verified occurrence of specified triggering events. ${ }^{31}$ Corporate dividends, interest payments, insurance payouts, and derivatives collateral management are some of the areas in which smart contracts potentially offer the most easily discernable optimization benefits. ${ }^{32}$

Smart contracts also enable so-called "initial coin offerings," or ICOs, in which various firms raise capital online by issuing digital tokens, or "coins," that carry various rights with respect to some future digital product or service the issuing firms intend to finance and develop. ${ }^{33}$ An ICO is essentially a new form of crowdfunding that, ideally, enables tech startups to raise funds directly from their user communities. ${ }^{34}$ Another form of digital crowdfunding is peer-to-peer, or marketplace, lending. ${ }^{35}$ The original idea behind today's marketplace lending

precise definitional boundaries among different categories of cryptocurrencies, crypto-assets, tokens, coins, etc. See Daniel Hinge, The Hunt for a Crypto Taxonomy, CENTRAL BANKING (May 4, 2018), https://www.centralbanking.com/central-banks/currency/digital-currencies/3494476/the-hunt-for-acrypto-taxonomy [https://perma.cc/7VN9-BPJ8] (highlighting definitional difficulties).

28. For a detailed discussion of Bitcoin, see infra Section III.A.1.

29. See id.

30. The term "smart contract" has no clear and uniformly accepted definition. Depending on context, it may refer either to a computer code stored, verified, and executed on a blockchain, or to a specific application of that code as an effective substitute for a legal contract. See Josh Start, Making Sense of Blockchain Smart Contracts, COINDESK (June 4, 2016), https://www.coindesk.com/making-sense-smart-contracts [https://perma.cc/UZJ7-JTTK].

31. Id.

32. See Salzman, supra note 3.

33. Many ICOs are functionally equivalent to securities offerings without the mandatory disclosure and other investor protection features required under U.S. securities laws. Accordingly, the applicability of federal securities laws and regulations to ICOs has been one of the hottest legal issues in the fintech space since 2016. See infra Section III.B.1.

34. See infra note 224 and accompanying text.

35. Marketplace lending is defined broadly as "any practice of pairing borrowers and lenders through the use of an online platform without a traditional bank intermediary." Marketplace Lending, FDIC SUPERVISORY INSIGHTS (Winter 2015), https://www.fdic.gov/regulations/examinations/supervisory/insights/siwin15/si_winter2015article02.pdf [https://perma.cc/CL8H-5RCR]. 
platforms, such as LendingClub, SoFi, and others, was to bring together individual and small-business borrowers and lenders, in order to create a truly decentralized and direct credit market. ${ }^{36}$ Not surprisingly, marketplace lending is often portrayed as a tool of "democratizing" finance by eliminating the need for banks and other financial intermediaries and by expanding access to credit.

The same "democratizing" impulse is commonly ascribed to the increasingly popular practice of robo-advising. ${ }^{37}$ Robo-advising denotes providing online financial advice with minimal or no human participation, using algorithmic asset allocation and trading models. ${ }^{38}$ Financial institutions' ability to replace expensive human advisors with cost-effective computer codes is seen as the tool of broadening access to previously exclusive wealth management services: everyone can invest in capital markets with robo-advisors' help. ${ }^{39}$

As this brief overview shows, all of the currently existing fintech applications, including cryptocurrencies, blockchain technologies, smart contracts, digital crowdfunding, and robo-advising, explicitly promise to "revolutionize" the provision of financial services. New digital technology unlocks new possibilities for fully frictionless transacting in a completely virtualized world, without the costs and delays associated with the use of professional financial intermediaries operating under multiple jurisdictions' rules. By making financial transactions infinitely faster, easier, and cheaper, fintech also offers new opportunities for financial inclusion and expanded access to financial services. In this sense, new technology seems poised to "revolutionize" finance not only as a matter of transactional efficiency but also as a matter of political economy. ${ }^{40}$

Yet, built into this narrative is a crucial presumption - sometimes explicit but often implicit - that the unfolding fintech "revolution" is a politically and normatively neutral phenomenon, a "win-win" situation not involving hard public policy choices and trade-offs. The prevailing attitude is to treat most of the problems commonly discussed in connection with fintech, such as cybersecurity concerns, network governance lapses, legal uncertainty, or regulatory gaps, much like natural "growing pains" accompanying society's triumphant march to a better future: benign temporary glitches ultimately resolvable through better coding or faster rule-writing.

Finance, however, is not politically or normatively neutral: money and power are two sides of the same coin. Finance is, and always will be, a matter of

\footnotetext{
36. For more on the evolution of marketplace lending, see infra notes 211-223 and accompanying text

37. For a discussion of robo-advising, see infra Section III.B.2.

38. See infra note 239 and accompanying text.

39. For a critical examination of this claim, see infra Section III.B.2.

40. See, e.g., Jeff Horowitz \& Eric Scro, Creating an Open Financial System and Why Institutionalization is Key, in KPMG, INSTITUTIONALIZATION OF CRYPTOASSETS 11 (Nov. 2018), https://assets.kpmg/content/dam/kpmg/us/pdf/2018/11/institutionalization-cryptoassets.pdf [https://perma.cc/SCU4-DA2C] (arguing that crypto may help overcome some of the most fundamental problems of the global financial system).
} 
utmost and direct public policy significance. Financial arrangements are fundamentally shaped by, and in turn shape, broader economic and political structures and choices. "Virtualizing" financial transactions does not change this basic fact; it only obscures it. Understanding the full significance of the fintech phenomenon, therefore, requires widening the lens beyond the immediate microtransactional effects of new technology to encompass the essential dynamics of the financial system as a whole.

To this end, it is critical to start by reminding ourselves of the core political arrangement that determines the principal structure and operation of today's financial system. In the U.S. context, it may be referred to as the New Deal settlement in finance.

\section{B. The New Deal Settlement in the Financial Sector}

The New Deal era was the pivotal moment in the emergence and development of the entire system of modern U.S. financial sector regulation and supervision. ${ }^{41}$ It was during this fateful period that Congress created a comprehensive system of disclosure-based federal securities regulation and a federal deposit insurance scheme, institutionalized the separation between banks and securities firms, and established numerous other legal and regulatory principles that continue to shape the operation of the U.S. financial system today. ${ }^{42}$ The purpose of this Article, however, is not to recount the specific financial sector reforms of that turbulent era but to distill the overarching principles that informed, guided, and found expression in the multitude of such reforms. This is what I call the New Deal settlement in finance. ${ }^{43}$

The New Deal settlement reflects certain politically derived judgments about the optimal balance of private freedom and public control in the financial markets. Several key features of the New Deal political settlement defined the substantive contours of the U.S. regulatory philosophy in the financial sector. At the highest level of generalization, the New Deal reforms institutionalized the broad concept of public interest-including public representation and public enforcement - as a legitimate factor in the daily operation of financial markets. The new regulatory philosophy explicitly acknowledged the overarching need (i) to protect the public from abusive market practices (as opposed to letting all market participants fend for themselves), (ii) to ensure that private financial markets should strive to serve the public's needs (as opposed to private market participants' needs alone), and (iii) to take the lead role in maintaining the

41. See Michael S. BARR, Howell E. JACKSON \& MARgARET E. TAHyAR, FinANCIAL REGULATION: LAW AND POLICY 47-52 (2016).

42. See id.; Omarova, supra note 10.

43. It is worth reiterating here that the Article concerns itself with the New Deal settlement only in the context of financial markets and regulation and not as a broader phenomenon in American political history and constitutional development. Nor does it claim to present a historical analysis of any particular aspect of the New Deal. See supra notes 12-15. 
integrity and healthy functioning of financial markets (as opposed to letting markets self-regulate). In pushing the public-private line in finance in this unprecedented way, the New Deal settlement was a political "disruption" of enormous significance.

And yet it didn't push the line too far into "public control" territory. The New Deal regulatory reforms left private actors firmly in control over substantive allocative decisions in financial markets, limiting the area of direct public control mainly to procedural and infrastructural support of the financial market's operations. With limited exceptions, the government's principal role was defined primarily as that of an outside regulator, the source and enforcer of the basic rules of fair play in financial markets. ${ }^{44}$ It was envisioned as a largely exogenous force with a limited mandate to influence private market actors' decisions on channeling credit and investment flows to specific uses. ${ }^{45}$ This principal delineation of public and private roles was reflected in and operationalized through such important regulatory choices as, for example, a deliberate rejection of merit-based financial product approval and a systematic preference for disclosure-based schemes. ${ }^{46}$ To put it simply, as long as the risks associated with a particular financial product were adequately disclosed, the government had little power to prevent the risky product from entering the market. ${ }^{47}$

As a result of this fundamental line-drawing between public and private roles in finance, the New Deal regulatory paradigm had an inherently micro, rather than macro, focus. Because private market participants, with their informational advantages and individualized economic incentives, were presumed to be superior decision-makers "on the ground," their judgments on risks and returns of particular financial transactions and products were not to be substituted by those of the regulators. To the extent regulators' judgments are, and are expected to be, driven by generalized public interest considerations rather than by any specific transactional "efficiencies," however, this policy choice set the context for a systematic prioritizing of micro-transactional factors

44. Of course, the New Deal era gave rise to many forms of direct government action inside, rather than merely outside, the ostensibly private financial markets. Perhaps the best example in this respect was the Reconstruction Finance Corporation (RFC), the once-powerful but now nearly forgotten federal instrumentality that played a critical role in maintaining the functioning of the nation's financial markets during the Great Depression. The extraordinary nature of this exception, however, only underscores the general rule. For an in-depth analysis of the RFC's role and institutional legacy, see Robert C. Hockett \& Saule T. Omarova, Private Wealth and Public Goods: A Case for a National Investment Authority, 43 J. CORP. L. 437 (2018).

45. See Robert C. Hockett \& Saule T. Omarova, Public Actors in Private Markets: Toward a Developmental Finance State, 93 WASH. U. L. REV. 103, 113 (2015) [hereinafter Hockett \& Omarova, Public Actors]; Robert C. Hockett \& Saule T. Omarova, "Private" Means to "Public" Ends: Governments as Market Actors, 15 THEORETICAL INQUIRIES IN L. 53, 54-55 (2014).

46. For in-depth discussion of financial product approval as a form of macroprudential regulation, see Saule T. Omarova, License to Deal: Mandatory Approval of Complex Financial Products, 90 WASH. U. L. REV. 63 (2012).

47. See Omarova, supra note 11 , at $95-97$. 
over macro-systemic ones and of individual action over collective agency. It is implicitly assumed that, if the former is taken care of, the latter will necessarily follow. ${ }^{48}$

Accordingly, the New Deal paradigm focused expressly on regulating individual financial firms, licensed and supervised under clearly identified regimes, based on the types of products they offered and activities they engaged in. ${ }^{49}$ The regulatory boundaries among financial institutions (banks, securities broker-dealers, insurers, etc.) and financial products (securities, banking products, insurance, commodity futures, etc.) were drawn in clear categorical terms. ${ }^{50}$ The silo-based regulatory architecture, in which separate administrative agencies oversee formally separate financial sub-sectors under different statutory schemes, was an institutional embodiment of this approach. ${ }^{51}$

At the same time, the New Deal reforms have also institutionalized the public's role as an explicit market backstop "of last resort." Perhaps the most readily recognizable example of this public safety net is the comprehensive federal deposit insurance scheme administered by the Federal Deposit Insurance Corporation (FDIC).$^{52}$ Another important example of the public's marketpreserving role is the central bank's expanded emergency authority to prop up not only banks but also broader financial markets. ${ }^{53}$ These political choices functionally transformed the government from a (presumably) exogenous rulemaker and enforcer into a direct financial market participant. ${ }^{54}$ Furthermore, these choices explicitly put the government - the quintessential political actor,

48. This is a basic logical error known as the fallacy of composition. For a theoretical and historically grounded account of the importance of macro-, as opposed to micro-, dynamics in financial markets, see Hockett, supra note 21; and Robert Hockett, Bretton Woods 1.0: A Constructive Retrieval for Sustainable Finance, 16 N.Y.U. J. LEGIS. \& PUB. POL'Y 401 (2013).

49. See Omarova, supra note 10 . The canonical example of this regulatory philosophy was the Glass-Steagall Act, which established a system of strict separation between commercial banking and investment banking. Banking Act of 1933, Pub. L. No. 73-66, 48 Stat. 162 (1933).

50. See Omarova, supra note 10; Gov. AcCOUnTABILITY OfFice, FinAnCial REGULATION: INDUSTRY CHANGES PROMPT NEED TO RECONSIDER U.S. REGULATORY STRUCTURE (Oct. 2004); Gov. AcCountability OfFice, Financial Regulatory ReForm: FinanCial Crisis Losses AND POTENTIAL IMPACTS OF THE DODD-FrANK ACT (Jan. 2013); GRP. OF THIRTY, THE STRUCTURE OF FinANCIAL SUPERVISION: APPROACHES AND CHALLENGES IN A GLOBAL MARKETPLACE (2008).

51. See supra note 50 .

52. See generally 12 U.S.C. $§ 1811$ et seq. (2018). The United States was the first jurisdiction to establish such a comprehensive deposit insurance regime. See Edward J. Kane \& Asli Demirguc-Kunt, Deposit Insurance Around the Globe: Where Does It Work? (Nat'l Bureau of Econ. Research, Working Paper No. 8493, 2001), https://www.nber.org/papers/w8493.pdf [https://perma.cc/EF2R-46N3].

53. See, e.g., Federal Reserve Act $\S 13(3), 12$ U.S.C. $\S 344$ (2018) (authorizing the Federal Reserve to provide emergency liquidity support to financial markets, subject to specified conditions). See also Lender of More than Last Resort, FED. RES. BANK OF MINNEAPOLIS: THE REGION (David Fettig ed., Dec. 2002), https://www.minneapolisfed.org/ /media/files/pubs/region/0212/lender.pdf [https://perma.cc/8P72-AZEB].

54. See Hockett \& Omarova, Public Actors, supra note 45 (discussing the taxonomy of roles governments perform in their capacities as market actors). 
the ultimate collective agency — in charge of preserving the stable functioning of financial markets. ${ }^{55}$

In consequence, there was, and still is, deep tension at the heart of the New Deal regulatory paradigm: it vests substantive control over the allocation of risks and returns in financial markets in private actors operating on a micro-level and assigns the responsibility for ensuring financial stability to public actors operating on a macro-level. Government regulation was designed to counteract and control the obvious moral hazard built into this system. In this sense, effective public oversight of financial markets and institutions was (and still is) critical to maintaining the New Deal political settlement. It is through close regulation and supervision of financial markets and institutions by specialized government agencies that the sovereign public was expected to keep profitseeking private market participants from abusing their micro-level freedom to generate macro-level risks.

The fundamental problem with this approach is that, in practice, allocation and modulation of credit and money in the financial system are intimately connected: systemically destabilizing asset price booms are the direct effect of socially suboptimal allocative decisions by individual market participants. ${ }^{56}$ The superficially neat functional separation of public and private, therefore, is inherently unstable. Beneath an intuitively clear division of functions, there are complex dynamics, conflicting interests, and ambiguous boundaries.

In effect, it may be said that the entire history of U.S. financial markets and regulation since the New Deal era has been the history of continuous renegotiation and readjustment of this delicate balance. Financial institutions and their clients, searching for higher profits and competitive edge, keep pushing the line toward greater private freedom to transact, to "complete" the perennially "incomplete" markets by creating and trading in new financial instruments. ${ }^{57}$ They often do so by exploiting gaps and ambiguities in the existing laws and regulations and by deliberately structuring transactions to escape the application of unfriendly legal rules, a technique widely known under the label of "regulatory arbitrage." 58

55. This essential hybridity is especially visible in the structure and operation of the modern banking system, which is best understood as a public-private partnership - or a franchise arrangement. For an in-depth analysis of how this arrangement works in practice, see Hockett \& Omarova, supra note 9.

56. See id.

57. A "complete system of markets" is one in which there is a market for every good. See Mark D. Flood, An Introduction to Complete Markets, 73 FED. RES. BANK OF ST. LOUIS REV. 32, 32 (1991), https://files.stlouisfed.org/files/htdocs/publications/review/91/03/Markets_Mar_Apr1991.pdf [https://perma.cc/VB7C-VFR5]. For the original theoretical account, see Kenneth J. Arrow \& Gerard Debreu, Existence of an Equilibrium for a Competitive Economy, 22 ECONOMETRICA 265 (1954).

58. The literature on the nature and role of regulatory arbitrage in the financial services sector is too voluminous to cite here. The rise of today's derivatives and repo markets, and the growth of money market mutual funds, for example, were direct products of regulatory arbitrage and of financial 
This constant injection of privately generated risks into the financial system creates quantitatively and qualitatively new challenges from the viewpoint of systemic stability, predominantly the public's responsibility. Inexorably, the public is in a reactive posture: once capital allocation decisions are made by private actors operating on a micro-level, the macro-level modulation comes into play as a principally ex post response. ${ }^{59}$ This fundamental logic both implicitly shapes, and is reflected in, the widely shared assumptions about the basic dynamics of finance. We take for granted that markets "evolve" and "innovate" (the primary, active, positive value-creation side of the public-private equation), while regulators "respond" and "react" (the secondary, passive, negative harmlimitation side). These assumptions define both the policy and the discursive agenda. How financial regulators do, or should, respond to privately driven financial innovation - and adjust regulatory tools and objectives to the new context - is one of the perennial questions that preoccupy scholars of financial markets and institutions. ${ }^{60}$ What goes unnoticed, however, is that this seemingly objective description of "how the world works" is itself, to a great extent, a product of a normative choice as to the relative competencies of private and public actors in financial markets. ${ }^{61}$

\section{Pre-Fintech Erosion of the New Deal Settlement: A Brief Recap}

Technology plays a critical role in this process of continuous renegotiation and resetting of the public-private balance in finance. It is well known, for example, that advances in computing and communications technology since the 1980s enabled the rapid growth of increasingly diverse and complex derivatives markets. Derivatives are bilateral contracts whose value is "derived" from that

firms' desire to circumvent specific regulatory constraints on their activities. For a recent book-length account of these dynamics, see ERIK GERDING, LAW, BUBBLES, AND FINANCIAL REGULATION (2013).

59. This is, of course, a generalization. The point here is not to say that every specific systemic stability enhancing measure is an ex post response to a specific transaction. Agency rules are prospective in their application. Banking regulation and supervision, in particular, involve regulatory agencies in private banks' balance-sheet management with the view toward preventing them from failure. Nevertheless, even in that context, the principal posture of the public oversight is not to substitute its own, public-interest based, substantive judgment for that of the bank's management in every instance when the bank is extending a loan or entering into a derivative contract. These types of direct credit-money allocation decisions are left to private bank managers. Regulatory limitations on individual banks' leverage, risk concentration, or liquidity position are designed to shape these choices only indirectly and, in this sense, are fundamentally reactive.

60. For a recent book-length treatment of this subject, see CRISTIE FORD, INNOVATION AND THE StATE: FinANCE, REgUlation, AND Justice (2017).

61. For an in-depth discussion and critique of this traditional delineation of roles in finance, see Hockett \& Omarova, Public Actors, supra note 45; Hockett \& Omarova, supra note 9; Hockett \& Omarova, supra note 44; Saule T. Omarova, Bank Governance and Systemic Stability: The “Golden Share” Approach, 68 ALA. L. REV. 1029 (2017). 
of some other underlying, or reference, asset. ${ }^{62}$ The commonly encountered derivatives are linked to commodities, securities, interest rates, or exchange rates. However, pretty much any quantifiable - and, importantly, fluctuatingvalue can serve as a reference asset. ${ }^{63}$ Derivatives enable financial market participants both to hedge their existing or anticipated risks and to make essentially speculative bets. While simple derivatives appear to have been in use even in ancient times, it was only in the 1980s that financial firms were able to use their newly acquired technological capabilities to scale up derivatives trades and turn them into one of the fastest growing segments of global financial markets. ${ }^{64}$

A similar story unfolded in the market for securitized products. "Securitization" generally refers to the practice of pooling revenue-generating assets, such as mortgage or credit card loans, and using the pooled assets as collateral backing the issuance of debt securities to investors. ${ }^{65}$ While not a recent invention, securitization became a major market-driving phenomenon in the 1980s, in large part because the advances in technology enabled originators and securitizers of loans to create much larger and more complex pools of securitizable assets and to manage the risk-return structure of debt securities backed by such assets. By the early 2000s, the market for these "structured" asset-backed products, including highly complex multi-layered schemes such as "collateralized debt obligations" (CDOs), grew to unprecedented levels. ${ }^{66}$ Moreover, the growth of securitization was intimately connected to the growth

62. See generally JOHN C. HULl, OptiOns, FUTURES, AND OtHER DERIVATIVES (9th ed. 2014); R. STAFFORD JOHNSON, INTRODUCTION TO DERIVATIVES: OPTIONS, FUTURES, AND SWAPS 110 (2009).

63. As a general rule, the more volatile the underlying asset's value, the more lucrative the related derivatives contract. Accordingly, derivatives contracts may be linked to things like inflation rates, natural catastrophes, or even financial market volatility itself.

64. There is a voluminous body of scholarly and popular literature detailing the history, economic functions, legal status, institutional structure, and financial stability implications of derivatives markets instruments. For a small sample, see Dan Awrey, The Mechanisms of Derivatives Market Efficiency, 91 N.Y.U. L. REV. 1104 (2016); Saule T. Omarova, The Quiet Metamorphosis: How Derivatives Changed the "Business of Banking," 63 U. MIAMI L. REV. 1041 (2009); Mark J. Roe, The Derivatives Market's Payment Priorities as Financial Crisis Accelerator, 63 STAN. L. ReV. 539 (2011); Lynn A. Stout, Derivatives and the Legal Origin of the 2008 Credit Crisis, 1 HARV. Bus. L. REV. 1 (2011).

65. See Kenneth C. Kettering, Securitization and Its Discontents: The Dynamics of Financial Product Development, 29 CARDOZO L. Rev. 1553, 1556 (2009); Jonathan C. Lipson, Re: Defining Securitization, 85 S. CAL. L. REV. 1229, 1257 (2012).

66. See generally FIN. CRISIS INQUIRY COMM'N, THE FINANCIAL CRISIS INQUIRY REPORT: FINAL REPORT OF THE NATIONAL COMMISSION ON THE CAUSES OF FINANCIAL AND ECONOMIC CRISIS IN THE UNITED STATES (2011), http://www.govinfo.gov/content/pkg/GPO-FCIC/pdf/GPOFCIC.pdf [http://perma.cc/T8LE-QL7]; S. PERMANENT SUBCOMM. ON INVESTIGATIONS, 112TH CONG., Wall Street and the Financial CRisis: ANatomy of a Financial Collapse (2011), http://hsgac.senate.gov/public/_files/Financial_Crisis/FinancialCrisisReport.pdf [https://perma.cc/7REBE2Q7]. 
of derivatives markets, mainly through the use of credit derivatives to structure asset-backed claims. ${ }^{67}$

Both derivatives and structured asset-backed products are heavily dependent on the capacity of their creators to run increasingly complicated computer models. ${ }^{68}$ The principal economic function of these and many other complex financial products is to allow for isolating, pricing, and trading specific risk factors embedded in, or constituting, the same otherwise indivisible asset. This process of synthetically constructing tradable financial claims out of deconstructed traditional assets - shares of stock, loans, or commoditiesrequires sophisticated analytical tools and computing power. ${ }^{69}$ As a result, today's highly structured financial products - marketed and used as both riskmanagement and risk-taking tools - are also, to a great extent, tech products. ${ }^{70}$

Importantly, however, the technology that enabled derivatives and other structured finance transactions was proprietary in character: developed and owned by financial institutions dealing and trading in these markets. That rendered the tech component of complex financial products less visible and more subsumed in their overall economic functions and effects. These economic functions and effects, of course, were often inseparable from the legal or regulatory functions and effects. Complex financial products are economically attractive not only because they allow for a more fine-tuned, bespoke tailoring of risks and returns of financial investments but also because they often lower the costs of such investments by circumventing specific laws and regulations. Accordingly, regulatory arbitrage is a strong driver of "innovation" in financial markets. ${ }^{71}$ Much of such innovation is, in fact, little more than a new way of avoiding regulatory limitations and compliance costs. ${ }^{72}$ Deregulatory policy choices, both formal and informal, further magnify and support these strategic shifts of financial activities from the traditionally "well-lit" regulated areas to unregulated "shadows" of the same economic markets. ${ }^{73}$

\footnotetext{
67. See S. PERMAnENT SubCOMM. ON InVESTIGATIONS, supra note 66.

68. See Erik F. Gerding, Code, Crash, and Open Source: The Outsourcing of Financial Regulation to Risk Models and the Global Financial Crisis, 84 WASH. L. REV. 127 (2009).

69. On the critical systemic significance of market actors' ability to synthesize new tradable assets, see infra Section II.B.

70. Such familiar terms as "financial engineering," "quants," "rocket scientists," and "legal technology" may, on some level, reflect an intuitive recognition of this underlying connection.

71. See supra note 58 and accompanying text.

72. See FORD, supra note 60; Dan Awrey, Complexity, Innovation and the Regulation of Modern Financial Markets, 2 HARV. BUS. L. REV. 235 (2012) (discussing supply-side incentives for financial institutions to engage in socially suboptimal "innovation" as a means of generating short-term monopoly-like rents).

73. For in-depth analyses of the hidden deregulation dynamics, see Omarova, supra note 64 (detailing how the national bank regulator, the Office of the Comptroller of the Currency, used informal decision-making tools to expand deposit-taking institutions' powers to trade and deal in derivatives instruments); Saule T. Omarova, From Gramm-Leach-Bliley to Dodd-Frank: the Unfulfilled Promise of Section 23A of the Federal Reserve Act, 89 N.C. L. REV. 1683 (2011) (detailing how the Federal Reserve used its informal administrative powers to loosen important statutory restrictions on
} 
This is in essence the familiar story of the emergence and growth of the controversial "shadow banking" sector. ${ }^{74}$ The term "shadow banking" does not have a firmly defined meaning and refers generally to a variety of financial markets and activities that mimic the economic substance of bank-like creditmoney creation without being subject to the same kind of regulatory oversight. ${ }^{75}$ Both derivatives and securitization markets are routinely cited as key examples of shadow banking in action: in both of these markets, various regulated and unregulated financial institutions continuously generated ultimately unsustainable levels of leverage and risk. ${ }^{76}$ This excessive risk-creation was at the root of the global financial crisis that began in 2008, when the elaborate system of complex structured products and derivatives sitting on top of risky subprime mortgages collapsed with a frightening speed.

A brief recap of this well-known narrative helps to highlight the more fundamental dynamics manifested in the rise of shadow banking: the gradual erosion of the New Deal settlement, as the contested public-private balance shifted toward an increasingly greater private freedom to make allocative decisions determining the types and levels of risk in the financial system, without the proportionately necessary increase in the public's ability to manage creditmoney aggregates. Moreover, while the sphere of public control over financial risk-generation diminished, the scope and scale of public accommodation of privately created liabilities in financial markets - both old and new, well-lit and pitch-dark - dramatically increased over the same period. ${ }^{77}$ The events of 20082009 sharply exposed the practical effects of this fundamental imbalance: privately created allocative distortions in financial markets led to unsustainable accumulations of risk and leverage in the system, and the public had to "clean up" the resulting mess. In this sense, the popular reference to "privatization of

banks' transactions with affiliated entities). For a broader account of the deregulatory dynamics in financial bubble-bust cycles, see GERDING, supra note 58.

74. There is a huge literature on shadow banking, especially in the post-2008 era when the term became synonymous with excessive systemic risk creation. For a small sample of this literature, see, for example, GERDING, supra note 58, at 395-470; Morgan Ricks, Money and (Shadow) Banking: $A$ Thought Experiment, 31 REV. OF BANKING \& FIN. L. 731 (2012); Tobias Adrian \& Hyun Song Shin, The Shadow Banking System: Implications for Financial Regulation (Fed. Res. Bank of N.Y. Staff Report No. 382, 2009); Tobias Adrian, Adam B. Ashcraft \& Nicola Cetorelli, Shadow Bank Monitoring (Fed. Res. Bank of N.Y. Staff Report No. 638, 2013); and Gary Gorton \& Andrew Metrick, Regulating the Shadow Banking System, 2010 BROOKINGS PAPER ON ECON. ACTIVITY, https://www.brookings.edu/wpcontent/uploads/2010/09/2010b_bpea_gorton.pdf [https://perma.cc/Q4TR-6K8M].

75. The term was coined by Paul McCulley. Paul McCulley, Teton Reflections, GLOBAL CENTRAL BANK $\quad$ FOCUS $\quad 2 \quad$ (Sept. http://www.sfindustry.org/images/uploads/pdfs/Paul\%20McCulley\%20Teton\%20Reflections\%202007.p df [https://perma.cc/E499-GGM8]; see also Bryan Noeth \& Rajdeep Sengupta, Is Shadow Banking Really Banking?, FED. RES. BANK OF ST. LOUIS: REGIONAL ECONOMIST 8-13 (Oct. 2011).

76. See sources cited supra note 74. For a more targeted discussion of the specific mechanisms through which shadow banking amplified credit-money aggregates, see Hockett \& Omarova, supra note 9 , at $1175-92$.

77. For a detailed analysis of this inevitable expansion of public accommodation, see Hockett \& Omarova, supra note 9, at 1175-92 
gains and socialization of losses"78 aptly captures the dynamics of erosion of the New Deal settlement in the financial sector.

The Dodd-Frank Act, the most far-reaching legislative reform in the U.S. financial sector since the New Deal, was an effort to curb some of the most visible manifestations of this imbalance. ${ }^{79}$ The Act explicitly sought to reinsert public agency and public interest in finance, among other things, by articulating the overarching policy goal of protecting systemic financial stability and by institutionalizing system-wide oversight of the financial sector. ${ }^{80}$ Yet, despite these important measures, the Dodd-Frank Act did not alter the substantive basis of the New Deal settlement, discussed above. ${ }^{81}$ Under the evolving post-crisis regime, much like in the pre-crisis era, the public still does not have any direct involvement in or control over allocation of financial capital, a traditional sphere of private dominance. In fact, by reconfirming this pre-crisis understanding of the relative competencies of private and public actors in financial markets, the Act further exacerbated the deep-seated tension within the New Deal paradigm.

\section{Fintech and the New Deal Settlement: Reframing the Inquiry}

It is in this context that the fintech revolution began to disrupt the way financial transactions are conducted and financial services are delivered. ${ }^{82}$ Its game-changing potential, however, extends beyond the pure transactional aspects of finance. This Article argues that fintech is emerging as a powerful new tool for resetting the current public-private balance in finance. Does it offer a unique opportunity to correct the structurally destabilizing imbalance between private generation of financial risk, on the one hand, and public accommodation of such privately generated risk, on the other? Or will it operate to intensify this imbalance? If it is the latter, does that mean that fintech is going to be the proverbial last nail in the coffin of the New Deal settlement in finance?

78. See, e.g., Joseph Stiglitz, U.S. Does Not Have Capitalism Now, CNBC (Jan. 19, 2010), https://www.cnbc.com/id/34921639 [https://perma.cc/U8HR-TDYV].

79. Dodd-Frank Wall Street Reform and Consumer Protection Act of 2010, Pub. L. 111-203, 124 Stat. 1376 (2010).

80. See David Skeel, The New Financial Deal: Understanding the DodDFRANK ACT AND ITS (UNINTENDED) CONSEQUENCES (2010); Omarova, supra note 11.

81. See supra Section I.B. Thus, the old silo-based structure of the financial sector oversight remains almost entirely intact. See Omarova, supra note 10. The new macroprudential regulatory regime essentially utilizes scaled up microprudential tools. See Robert Hockett, The Macroprudential Turn: From Institutional 'Safety and Soundness' to Systematic 'Financial Stability' in Financial Supervision, 9 VA. L. \& BUS. REV. 201 (2015). And, to the extent Dodd-Frank seeks to restrain potential risks posed by derivatives and other structured products, it does so only indirectly, through demanding greater disclosure, encouraging standardization and centralized clearing, and incentivizing more prudent risk underwriting by private parties. See Omarova, supra note 11, at 96-97; Awrey, supra note 64 .

82. See supra Section I.A. 
These questions help to reframe the key inquiry into the nature and systemic impact of fintech. Ultimately, understanding fintech as a systemic phenomenon (as opposed to a mere collection of discrete finance-related applications of digital technology) requires analyzing whether, and how, specific fintech applications affect the public's capacity to maintain the stability of the macro-environment. This reframing allows us to overcome the current fragmentation of the fintech debate by redirecting it away from the familiar but largely unproductive themes. ${ }^{83}$ It also enables us to situate fintech in the broader analytical and normative context as an integral part of, or the latest phase in, the decades-long process of gradual renegotiation of the New Deal settlement in finance.

The fundamental continuity in this process is hard to miss. Despite its disruptive appearance, today's digital technology largely facilitates and amplifies certain long-standing trends in modern finance. In this sense, it is a continuation of the core pre-fintech dynamics in financial markets, whose cumulative effect to date has been the gradual "unsettling" of the New Deal settlement. At the same time, however, qualitatively new technological tools can elevate these built-in tensions to a qualitatively new level, potentially demanding a qualitatively new political settlement.

This means that fintech is properly conceptualized not so much as "revolutionizing" finance as providing new channels for the operation of the fundamental financial market dynamics predating it. From this perspective, it is important to resist the obvious temptation to focus on superficially novel, microtransactional aspects of fintech. In the final analysis, the systemic significance of the unfolding fintech revolution is in its (not yet fully known) potential to redefine the basic patterns of interaction between the private and the public sides of modern finance.

Accordingly, the first step toward understanding fintech as a systemic rather than as transactional, or micro-level, phenomenon is to re-examine from the new vantage point the underlying drivers of the changing public-private balance in finance. The project of decoding the fintech revolution thus begins with reassessing what we already know about the functioning, and malfunctioning, of financial markets and institutions, in light of what we are learning about new finance-related technologies.

So, what exactly do we know about the functional dynamics of finance?

83. One example of such a familiar theme is so-called "disintermediation" of incumbent financial institutions by fintech entrants. While these types of shift in the structure of specific market segments undeniably raise important regulatory issues on a more granular level, conceptualizing the broader fintech dynamics in terms of "disintermediation" is needlessly reductionist. 


\section{The Logic of Financial Innovation and the Erosion of the New Deal}

\section{A. Focusing the Inquiry: Secondary Markets in Financial Instruments}

As discussed above, one of the key features of the New Deal settlement in finance was that it left the critical task of credit- or capital-allocation to private market actors. ${ }^{84}$ In this system, private actors have the ultimate power to decide which financial instruments to sell or to buy, or which risks to generate or to take on, and at what price. The government generally does not control these decisions, as long as the relevant private parties make required disclosures and otherwise conduct their businesses in accordance with the applicable rules. ${ }^{85}$

Instead, under the terms of the New Deal political bargain, the government's principal role is to provide macro-stability, not only by regulating but also by directly backing private financial markets. ${ }^{86}$ This public accommodation of privately created risks and liabilities is the defining dynamic in a modern financial system: one that can be traced throughout all of that system's interconnected layers and that ultimately underwrites the growth of putatively private capital markets. ${ }^{87}$

Inevitably, however, public accommodation also creates powerful structural incentives for over-generation of financial risks by rent-seeking private parties. ${ }^{88}$ It incentivizes the creation and proliferation of financial products - and the related growth of secondary markets in which such financial products are traded. This built-in incentive for constant reproduction and growth of secondary markets is a fundamental, and fundamentally underappreciated, driver of what is routinely understood as "financial innovation."

Standard accounts of finance, by contrast, use primary markets as the archetypal setting in which "financial intermediation" takes place: the savers of

84. See supra notes $44-47$ and accompanying text.

85. This is true despite the fact that federal laws and regulations impose limits on the ability of the least sophisticated, and therefore most vulnerable, financial market participants to invest in certain high-risk financial instruments. For example, under the U.S. regime of securities regulation, retail investors are not allowed to invest in privately placed securities pursuant to SEC Rule 144A, which limits permissible purchasers to institutional investors. See 17 C.F.R. § 240.144A (2018). Similarly, retail investors cannot invest directly in hedge funds, private equity funds, or other funds exempt from registration and regulation as "investment companies" under the Investment Company Act of 1940. See 15 U.S.C. $\S 80 \mathrm{a}-3(\mathrm{c})(7)$ (2018). All of these investor-protection measures, however, operate primarily to draw the intra-sectoral lines separating more strictly regulated retail markets from institutional, or wholesale, markets subject to much lighter oversight. They do not—nor were they ever intended to-put the regulators in charge of making specific investment choices on behalf of retail market participants.

86. See supra notes 52-55 and accompanying text.

87. For a detailed explanation of what I mean by "public accommodation," a capacious concept that goes far beyond federal deposit insurance or bank bailouts, see Hockett \& Omarova, supra note 9. It is this public accommodation - often unseen or taken for granted - that fundamentally enables and underwrites the financial flows in the system: from the banking sector, through capital markets, to the outer edges of the constantly evolving "shadow banking." See id.

88. See id. 
money extend loans or invest in the equity of the users of funds, with the mediating help of a professional financial intermediary. ${ }^{89}$ The intermediarysuch as a bank, a securities dealer, or an investment fund-is said to "transform" all or some of the key risk attributes embedded in the transaction. This is what is typically described as maturity, liquidity, or credit risk transformation: a set of functions typically performed by banks, the quintessential "intermediaries," and replicated in part by non-bank financial institutions. ${ }^{90}$

This narrative, which remains the dominant intellectual framework for analyzing the financial system dynamics, is fundamentally misleading. ${ }^{91}$ Among other things, it masks the independent significance, and indeed de facto primacy, of secondary-market dynamics in the modern financial system. In primary market transactions, the entrepreneurial users of capital issue securities and incur loans primarily for the purpose of funding non-financial economic enterprise, thereby taking capital out of the financial system and putting it to productive use in the real, i.e., non-financial, economy. ${ }^{92}$ This feature of primary markets operates as the key safety valve that keeps the financial system from outgrowing the economy's capacity to absorb capital at any given moment. In this sense, primary markets' ability to generate financial claims, and thus financial risks, is inherently subject to certain externally determined limits.

In the vast majority of real-life financial transactions, however, market players borrow and issue various financial claims in order to invest in other financial claims. Unlike primary market issuances used to fund companies' investments in operating assets, secondary market transactions fund investments in financial assets. This seemingly trivial difference has critical consequences. Thus, largely as a result of the legal and financing technologies developed specifically for this purpose, there is no natural (i.e., independent from the

89. This is, literally, a textbook understanding of "financial intermediation." See ZVI BOdie \& Robert C. MERTON, FinANCE 22-23 (2000); RichaRD SCOTT CARNELl ET AL., THE LAW OF FINANCIAL INSTITUTIONS 37 (5th ed. 2013); BARBARA CASU ET AL., INTRODUCTION TO BANKING 18

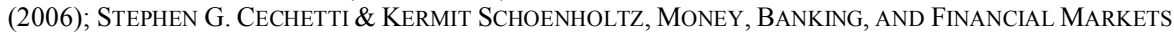
39 (3d ed., 2008); STUART I. GREENBAUM \& ANJAN V. THAKOR, CONTEMPORARY FINANCIAL INTERMEDIATION 55-58 (2007); KENT MATHEWS \& JOHN THOMPSON, THE ECONOMICS OF BANKING 33 (2005).

90. References to credit, maturity, and liquidity transformation as the core functional features of banking and, by extension, "shadow banking" are too ubiquitous to cite. What is interesting for the purposes of the present discussion is that this conceptual apparatus presupposes a specific purpose behind the intermediated transaction: moving capital from the investor-saver's hands into the hands of a productive user-entrepreneur. While not stated explicitly, an implicit presumption here is that the user is seeking funds for some legitimate economic use and not for a speculative financial reinvestment.

91. For a detailed explanation of why the "financial intermediation" orthodoxy is fundamentally misleading, see Hockett \& Omarova, supra note 9.

92. Of course, as business entities, financial institutions also raise capital by issuing securities in primary markets or borrowing money. The point here is that, in the standard picture of how capital markets operate, companies issue equity and raise debt in order to support or expand their "realeconomy" business operations that generate jobs and wealth. This is the implicit normative justification for financial intermediation as a socially valuable activity. It is difficult to overestimate the significance of this implicit normative assumption. 
operation of the financial market itself) limit on the volumes of financial claims (i.e., financial liabilities) traded in secondary markets. In principle, an unlimited number of market participants can enter into an unlimited number of secondary market transactions involving an unlimited variety of financial claims and liabilities. To the extent these privately created claims/liabilities are publicly accommodated, either directly or indirectly, they amplify both private market participants' rents and the public's aggregate risk exposure-potentially indefinitely.

This basic relationship explains why today's secondary markets in financial instruments are the principal sites of both relentless transactional "innovation" and chronic over-generation of systemic risk. ${ }^{93}$ It also explains why secondary markets in financial assets currently dwarf primary markets in terms of size, complexity, and systemic significance. ${ }^{94}$ This is both a structural and a functional imbalance. In theory, secondary markets' main function is to support and facilitate primary capital markets by providing liquidity, price discovery, and risk-shifting (including exit) opportunities for primary market participants. ${ }^{95}$ In practice, secondary market trading often determines the terms and volumes of primary issuances of financial claims. The rapid rise of unsustainably risky subprime mortgage lending in the early 2000s, in response mainly to the rising demand for such loans as the raw material for MBSs and CDOs, provides a vivid example of these inverted dynamics. ${ }^{96}$

Yet, the significance of this shift in the financial system's center of gravity from capital-raising in primary markets to risk-trading in secondary markets has not been fully appreciated and examined in the academic and policy discussions to date. Even in the post-crisis era, the "financial intermediation" discourse effortlessly glides over the fundamental differences between primary and secondary market dynamics, blending them together under the superficially

93. It is telling, for example, that even financial asset classes traditionally and functionally viewed as not designed for, or amenable to, secondary market trading are currently traded in burgeoning secondary markets. Market liquidity is quickly becoming a universal attribute of all financial claims. See, e.g., Javier Espinoza, Secondary Private Equity Deals Near Record, Fin. TIMES (July 30, 2017), https:/www.ft.com/content/2f844682-7507-11e7-a3e8-60495fe6ca71 [https://perma.cc/N2FF343Z] (describing record levels of secondary market trading in traditionally illiquid private equity investments).

15

94. See, e.g., World Federation of Exchanges, 2017 Full Year Market Highlights (Feb. 2018), https://www.worldexchanges.org/storage/app/media/research/Market $\% 20$ highlights/WFE $\% 20 \mathrm{FY} \% 202017 \% 20 \mathrm{Market} \% 20$ Highlights.pdf [https://perma.cc/2S8L-N8NN] (providing a statistical breakdown of annual trading volumes on global exchanges).

95. This Article does not dispute the fact that, on a micro-transactional level, secondary trading functions as a critical price discovery and liquidity creation mechanism. The point here is that, alongside these well-known and much discussed benefits of vibrant secondary market trading, there are also far less salutary_and potentially far more publicly salient—macro-systemic dynamics built into these markets' operation.

96. See sources cited supra note 66; GARY GORTON, SLAPPED BY THE INVISIBLE HAND: THE PANIC OF 2007 (2008) 
descriptive labels of various balance-sheet "transformation" functions. ${ }^{97}$ Within these discursive parameters, the principal focus of the mainstream policy debate is on potential means of fortifying financial intermediaries' balance sheets, whose inherent fragility is presumed to be a necessary feature of a thriving financial system. This normative and conceptual stance, in turn, heavily favors self-consciously technocratic approaches to both analyzing developments in financial markets and framing regulatory responses.

To overcome this persistent myopia, and to develop a fuller and deeper understanding of the systemically destabilizing logic of financial innovation, it is necessary to refocus the inquiry on the core dynamics in secondary markets for financial products. In doing so, it is important to move beyond the familiar descriptions of maturity or liquidity "transformations" appearing on, or off, various balance sheets. Instead of dissecting how various firms "intermediate" in various transactional contexts, we should shift our efforts toward identifying and examining the principal mechanisms and techniques that enable private actors to create and grow - continuously and virtually unconstrainedsecondary markets for financial risk trading..$^{8}$ Constructing a taxonomy of these secondary market mechanisms serves a particularly significant purpose in the context of this Article: it provides a conceptual framework for analyzing the potential impact of specific fintech applications on the long-term stability and resilience of the financial system. ${ }^{99}$

\section{B. The Mechanisms of Secondary Market Proliferation: A Preliminary \\ Taxonomy}

As argued above, the fundamental division of roles built into the New Deal settlement creates structural incentives for the disproportionate growth of secondary markets in tradable financial assets. ${ }^{100}$ The bulk of these tradable assets are "produced" for reasons that have little to do with "capital formation" (or canonical capital allocation) in primary markets. To put it simply, financial products are bundles of financial risks and returns manufactured by financial institutions for sale to other market participants, mainly portfolio investors or managers.

From a micro-level transactional perspective, this is typically viewed as a valuable financial service. We are all familiar with the standard vocabulary that

97. "Maturity" or "liquidity" transformation is the same balance-sheet phenomenon in any transactional setting. In the canonical primary-market context of banking, this structural balance-sheet fragility is believed to serve a socially beneficial purpose, thus justifying an explicit public backup for banks. The same logic is then easily extended to the same types of balance sheet fragility resulting from secondary market activities.

98. For the ease of reference, and unless otherwise specified, the following discussion will refer to secondary markets in financial instruments as simply "financial markets."

99. See infra Part III.

100. See supra notes 87-96 and accompanying text. 
conveys this normative assessment in terms of "providing liquidity," "completing markets," "discovering prices," "enabling diversification and risk management," or "creating portfolio-enhancement opportunities." From a macro-level systemic perspective, however, the principal consequence of this continuous manufacturing of financial products is the continuous injection of privately created financial risks into the system. Yet, we do not currently have a sufficiently extensive and well-established vocabulary to articulate this systemic perspective as a valid counterpoint to the dominant transactional view of financial markets' operation. ${ }^{101}$

Developing such a vocabulary is no easy task. It requires taking a fresh look at the familiar phenomena in an effort to identify important overarching trends and dynamics that were either unnoticed or unappreciated in previous accounts. ${ }^{102}$ It requires a new narrative that helps to explain how, and through which mechanisms, secondary markets in financial instruments are able to grow and proliferate. ${ }^{103}$ As the first step in this direction, this Article offers a preliminary taxonomy of core dynamics operating in secondary markets for financial instruments. ${ }^{104}$

\section{The Market's Modus Operandi: Synthesizing and Scaling Up}

At the most abstract level, the growth of financial markets is best understood by reference to two interrelated practices: (1) synthesizing financial assets and (2) scaling up transactional activity. To put it simply, both the scope and the scale of financial markets increase when (1) more products can be purchased and sold, and (2) more trades can be made in these markets.

The practice of synthesizing financial assets typically involves creating new types of financial claims out of the existing ones. Some of the most basic and familiar examples include creating tradable stock indices, writing options on gold or shares of common stock, securitizing loans, and even setting up mutual

101. In our previous work, Robert Hockett and I have begun this project of developing a new conceptual vocabulary of modern finance as a systemic phenomenon. See, e.g., Hockett \& Omarova, supra note 9; Hockett \& Omarova, Public Actors, supra note 45.

102. See sources cited supra note 101.

103. There is, of course, a well-known (though not entirely uncontested) narrative of how various market innovations in recent decades-including money market mutual funds, wholesale derivatives and repo markets, and complex securitized products - emerged in response to, and were enabled by, specific legal and regulatory developments. See supra Section I.C. This Article neither replicates nor challenges that story. Instead, it seeks to take the analysis to a higher level of abstraction by drawing out the broader - more fundamental and unifying - dynamics behind these and many other developments.

104. Any attempt to construct such a taxonomy inevitably runs into various definitional and boundary-drawing difficulties. The constant growth and complexification of financial markets is a multi-level process, with a seemingly infinite variety of elements and factors interacting in a seemingly infinite variety of ways. It is nearly impossible to isolate any specific element or factor with surgical precision. Instead, the focus of the present taxonomy-building exercise is on the fundamental logic behind this multitude of factors. 
funds. In all of these cases, a relatively small range of traditional financial assets, including common stock, corporate bonds, loans, or commodities, serve as the base on which a potentially unlimited number of new types of financial claims are created. Importantly, the standard economic logic of supply and demand does not constrain this process. An increasing supply of tradable assets - or items on the menu of choices available to financial market participants - generates an increasing demand for them, which in turn incentivizes more assetsynthesizing. ${ }^{105}$ And leverage plays the critical role in enabling this iterative supply-demand pattern. ${ }^{106}$

The resulting proliferation of tradable financial claims is itself an important measure, and a determinant, of the quantitative growth of financial markets. The concept and practice of "scaling up" (i.e., increasing the volume and velocity of transacting) is another fundamental determinant of such growth. Scaling up is achieved through a wide variety of means. Market infrastructure and transactional technologies are of special importance in this respect. For example, centralized trading platforms (formally registered exchanges, alternative trading networks, or dealer-run private pools), clearinghouses, and payment systems all enable far greater volumes of trading to take place at greater speeds than would otherwise be achievable. Similarly, greater standardization of financial instruments helps to increase the volume of trading, at times dramatically, as in the case of the International Swaps and Derivatives Association (ISDA) documentation for derivatives contracts. ${ }^{107}$ The ISDA example also shows how targeted changes in the applicable legal regimes can effectively unlock the growth of entire markets for financial products. ${ }^{108}$ Finally, algorithmic trading is perhaps the most readily available example of rapid rise in the velocity (and, by extension, volume) of transactions as a result of the sheer expansion in technological capacity. ${ }^{109}$

Synthesizing financial assets and scaling up financial transactions are two fundamentally systemic practices, universal modes of operation at the very core of financial markets' logical design. Not surprisingly, they both have profound

105. See sources cited supra note 72.

106. In that sense, today's high finance may be said to follow the Starbucks business model, in which the constant invention and marketing of new, intentionally and carefully differentiated, products creates its own demand. Just like the Starbucks designer beverages, most complex financial products are made using the same basic ingredients. Leverage, of course, functions much like caffeine in that it keeps everyone coming back for more.

107. See Complete ISDA Documentation Package, INT'L SwAPS \& DERIVATIVES Ass' $\mathrm{N}, \quad$ https://www.isda.org/book/complete-isda-documentation-package [https://perma.cc/95C6C7W9].

108. This refers specifically to ISDA's successful campaign to secure preferential treatment of derivatives under the U.S. Bankruptcy Code, as well as under many other jurisdictions' insolvency laws. See Steven L. Schwarcz \& Ori Sharon, The Bankruptcy-Law Safe Harbor for Derivatives: A Path-Dependence Analysis, 71 WASH. \& LEE L. REV. 1715 (2014).

109. For a general overview of algorithmic trading and issues it raises under U.S. securities laws, see, e.g., Steven R. McNamara, The Law and Ethics of Algorithmic Trading, 17 MiNN. J.L. SCI. \& TECH. 71 (2016); Yesha Yadav, How Algorithmic Trading Undermines Efficiency in Capital Markets, 68 VAND. L. REV. 1607 (2015). 
structural implications. Thus, the introduction of new financial products often leads to the emergence of new specialized markets in which they are traded. New actors may enter these newly created markets, both on the sell and on the buy sides, while the established financial institutions may assume new roles in them. New patterns of market concentration and systemic interdependencies take shape. Via the multitude of specific transactional channels through which the twin imperatives of synthesizing and scaling up operate, the financial market grows not only bigger and faster but also more structurally complex.

It is, of course, impossible and ultimately unnecessary to enumerate all of these specific channels. It is nevertheless helpful, for analytical purposes, to identify the key mechanisms market participants use to synthesize financial assets and to scale up financial transactions.

\section{The Four Mechanisms of Synthesizing Assets and Scaling Up Trading} Activity

At first approximation, there are four such mechanisms that may be broadly — and inevitably somewhat imprecisely — termed "pooling," "layering," "acceleration", and "compression." These analytical categories refer not to any particular type of product or transaction but rather to system-level operational principles, or core techniques that enable financial markets' continuous reproduction and expansion. In this sense, each of these categories may be seen as a transactional meta-technology, an embedded system functionality supporting a wide variety of individual applications.

\section{a. Pooling}

Pooling and layering are closely related, though conceptually distinct, mechanisms of synthesizing financial assets and scaling up trading. As used here, "pooling" denotes the familiar technique of combining multiple financial assets with certain shared characteristics, for the purpose of creating a new set of financial claims backed by, or determined by reference to, the resulting asset pool. This is perhaps the most ubiquitous technique in finance. Mutual funds and other collective investment vehicles are products of explicit pooling of other financial instruments - corporate stocks, bonds, and other claims issued in primary markets - in a portfolio used to back the issuance of fund shares to investors. Shares issued by individual funds, in turn, can be pooled in a so-called fund-of-funds (FoF) portfolio backing the issuance of the FoF shares. ${ }^{110}$

Benchmarking and creation of indices constitute a similarly ubiquitous, albeit less directly visible, system-level method of pooling securities issued in

\footnotetext{
110. See, e.g., Fund of Funds, MANAGED Fund Ass'N, https://www.managedfunds.org/hedge-fund-investors/fund-of-funds [https://perma.cc/U56H-Q9TK].
} 
primary markets for purposes of synthesizing new tradable assets in secondary markets. ${ }^{11}$ Among other things, major stock indices, like the S\&P 500 or the Wilshire 5000, are used as benchmarks for-and therefore enable the emergence of - a wide variety of mutual and exchange-traded funds (ETFs) that track their benchmark index values. ${ }^{112}$

\section{b. Layering}

The last two examples of pooling, FoF and indices, also illustrate the role of another transaction meta-technology, which may be called layering. I use the term "layering" to refer to the technique of synthesizing financial assets in a manner that creates a chain of hierarchically linked claims, so that the performance of each new asset "layer" is determined by reference to the combined performance of pooled financial assets underlying it.

As this description makes clear, the layering technique often involves pooling, which makes these categories difficult to separate neatly. Nevertheless, as pooling is repeated in several consecutive rounds, the distinct systemic implications of the resulting multi-layered structure built on the same set of underlying claims become increasingly pronounced. It is easy to see, for instance, how shares in a particular investment fund can get bundled with other funds' shares in the first-layer FoF, whose shares in turn get bundled with other FoF shares in the second-layer FoF portfolio, whose shares then get bundled with yet another set of FoF shares in the third-layer FoF, and so on. At each level, an entirely new crop of tradable fund shares is created, regardless of whether or not there are any additional issuances of corporate securities in the primary market.

Securitization provides an even more vivid example of synthesizing new tradable assets via pooling and layering. In a typical securitization, a special purpose vehicle (SPV), which holds a portfolio of loans or other revenueproducing assets, issues tradable asset-backed bonds (ABS). ${ }^{113}$ These ABS are then re-bundled with other ABS in the next layer of securitization, such as a $\mathrm{CDO}$, which issues several tranches of its own bonds. These bonds are then used as collateral backing bonds issued in a further layer of securitization, so-called CDO-squared, followed by CDO-cubed, and so on. ${ }^{114}$

Derivatives provide yet another canonical example of how the layering mechanism is used both to synthesize new assets and to scale up market trading. Derivatives are contingent claim contracts that determine counterparties' rights

111. For a discussion of the systemic function of benchmark prices and indices, see Robert C. Hockett \& Saule T. Omarova, Systemically Significant Prices, 2 J. Fin. REg. 1 (2016).

112. See Vladislav Sushko \& Grant Turner, The Implications of Passive Investing for Securities Markets, BANK FOR INT'L SETTLEMENTS Q. Rev. 113 (Mar. 2018), https://www.bis.org/publ/qtrpdf/r_qt1803j.pdf [https://perma.cc/DH4C-FQ4X].

113. See supra notes 64-65 and accompanying text.

114. See sources cited supra note 65. 
and obligations by reference to the changes in the value of specified underlying assets. ${ }^{115}$ Because the underlying asset is merely a reference point for calculating contractual payouts, there is no theoretical limit on counterparties' ability to enter into as many derivatives contracts as they desire, on any terms they choose. ${ }^{116}$ In this sense, derivatives are the ultimate tools for synthesizing a potentially infinite number of tradable financial products on top of any single underlying asset.

Indexing and benchmarking, mentioned above in connection with pooling, also allow for layering of tradable assets in a manner similar to derivatives. A major stock or commodity index, for example, enables the creation of a wide range of tradable products tracking it. ${ }^{117}$

All of the examples above underscore two key features of layering as an embedded system-level functionality.

First, layering enables a finite quantity of existing financial claims to serve as the base on which potentially infinite quantities of new financial claims can be produced. Thus, layering significantly blunts, if not eliminates, the fundamental structural constraint on the growth of secondary financial markets: the exogenously limited volume of instruments issued in the primary markets.

Second, layering produces highly complex interdependencies among the seemingly discrete assets and markets. Financial assets that constitute a single product chain do not have to be linked other than through value-derivation: they don't have to be issued by the same or similar entities or reference same or similarly sourced cash flows. The many different layers of financial products may be inherently connected, yet the precise patterns of correlation among their values may be difficult to discern.

\section{c. Acceleration}

While pooling and layering operate as the essential determinants of financial markets' structural complexity, the most visible and direct role of acceleration and compression is to amplify and sustain the growing volume and velocity of trading.

Acceleration occurs whenever the speed of transacting is increased (the velocity of trading), thus allowing more trades to be executed (the volume of

\footnotetext{
115. See supra notes 62-63 and accompanying text.

116. In practice, of course, there are various limits on that ability, including regulatory ones.

117. For instance, the emergence of specialized commodity price indices in the late 1990s-early 2000s has been identified as a major factor behind the surge in financial investors' participation in commodities markets and the related growth of trading in commodity-linked financial instruments. See Scott H. Irwin \& Dwight R. Sanders, Index Funds, Financialization, and Commodity Futures Markets, 33 APP. ECON. PERSP. \& POL'Y 1 (2011); Ing-Haw Cheng \& Wei Xiong, The Financialization of Commodity Markets (Nat'l Bureau of Econ. Research, Working Paper No. 19642, 2013), http://www.nber.org/papers/w19642 [https://perma.cc/ENR9-LE2X].
} 
trading). Perhaps the most easily recognizable example of acceleration as a mechanism of scaling up financial transactions is algorithmic, or high-frequency, trading (HFT). HFT is a trading strategy that uses complex algorithms to execute trades at speeds far exceeding human ability. In essence, HFT uses quantitative investment programs to take extremely short-term positions in equities, currencies, and any other electronically tradable financial instruments, and to move in and out of such positions as a way of capturing extremely small gains on every trade. ${ }^{118}$ By definition and design, HFT strategies dramatically, and successfully, accelerate and amplify trading activity in the relevant markets. ${ }^{119}$

The acceleration mechanism also works in less obvious ways, often in conjunction with the pooling and layering mechanisms. The very act of synthesizing a new tradable asset may help to increase the aggregate volume and velocity of market transactions. The creation of a new asset eliminates potentially significant transactional costs of placing multiple trades that would otherwise be required in order to achieve the same economic exposure. It makes trading faster and cheaper relative to trading in the underlying assets themselves, which in turn leads to surging levels of trading activity. Indexing, derivatives, securitizations, and many other financial instruments and market practices exemplify these dynamics.

Standardizing tradable instruments and trading practices is another important tool of accelerating financial transactions. The logic of this acceleration tool is simple: eliminating idiosyncratic variations in the key economic terms of a particular category of financial products significantly reduces the amount of time and resources that need to be spent on each individual trade. By establishing a common baseline, it also makes easier and faster to craft bespoke varieties of the same product, if need be. ${ }^{120}$ In short, secondary markets need standardization because of its transaction-boosting potential: standardization means faster trades, and more of them.

\section{d. Compression}

I use the term "compression" to refer generally to the technique of aggregating and compacting risk exposures and obligations associated with

118. See Irene Aldridge, What Is High-Frequency Trading, After All?, HUFFINGTON Post (July 8, 2010), https://www.huffingtonpost.com/irene-aldridge/what-is-high-frequencytr_b_639203.html [https://perma.cc/Z9Z5-MVMA].

119. Id.

120. As mentioned above, a well-known example of this kind is ISDA's success in creating an industry-wide set of standard documentation for over-the-counter (OTC) derivatives. See supra notes 107-108 and accompanying text. A much earlier and equally powerful example comes from the New Deal era, when the newly established Federal Housing Administration (FHA) used its power as the national provider of mortgage default insurance to encourage the adoption of a 30-year fixed-rate mortgage loan as the new industry standard. The FHA's standard-setting actions played a critical role in facilitating the subsequent creation of the national secondary market for home loans. See Hockett \& Omarova, Public Actors, supra note 45, at 133-34. 
multiple trades in a manner that de facto transforms them into a single economic transaction.

In this sense, it is broader than "trade compression," a term of art denoting a common practice in derivatives trading that, quite simply, involves reducing the number of derivatives contracts while keeping the same net economic exposure. ${ }^{121}$ In a typical compressed trade, several derivative contracts between the same counterparties are torn up and replaced with a single contract with a reduced (often, quite significantly) notional amount. ${ }^{122}$ Compressing simplifies a complex transactional pattern by extracting and operationalizing its aggregate economic effect on the counterparties and reducing their gross risk exposures. By the same token, however, compression effectively hides the actual volume of transacting that took place between these counterparties. While the former is the intended micro-level transactional effect of compression, the latter is its less obvious but significant macro-level effect.

The same basic principle operates in the broader market context through the common practice of netting. Generally, netting involves offsetting the mutual payment obligations of transacting parties in order to facilitate the back-office process of clearing and settling multiple trades between them. ${ }^{123}$ Netting does not directly generate any new financial liabilities or assets: it merely simplifies their ultimate settlement by eliminating unnecessary flows of funds and associated frictions in the process. This optimizing and risk-reducing function of netting is well known and widely acknowledged. ${ }^{124}$

By replacing multiple gross transfers due throughout the day with a single net transfer at the end of it, however, netting also enables a far greater amount of trading to take place. From that perspective, the widespread use of netting and trade compression has an important, and routinely under-appreciated, systemic effect: it empowers financial market participants to engage in secondary market trading on a far greater scale, and at far greater speeds, than would be sustainable in the less forgiving world of gross settlement of trading obligations. ${ }^{125}$ In this

121. See Trade Compression, DeRIVATIVEs Documentation (Nov. 20, 2015), https://www.derivsdocu.com/blog/2015/11/20/trade-compression [https://perma.cc/2XPW-32VJ] (explaining trade compression in over-the-counter derivatives markets).

122. Trade compression can also be done on a multilateral basis. Id

123. Netting is also used to offset other obligations, such as those related to the posting of collateral under derivatives or repo agreements.

124. There is a vast literature, both academic and industry-produced, explaining the advantages of netting from the perspective of reducing credit, settlement, liquidity, and other risks. See, e.g., Netting and Offsetting: Reporting Derivatives Under U.S. GAAP and Under IFRS, INT'L SWAPS \& DERIVATIVES ASS'N (May 2012), https://www.isda.org/a/veiDE/offsetting-under-us-gaap-and-ifrs-may2012.pdf [https://perma.cc/L959-XFKH].

125. A related form of compression is so-called portfolio margining, a common market practice that allows for the netting of certain positions in a portfolio of derivatives or other financial instruments for purposes of calculating minimum collateral requirements. In simple terms, portfolio margining seeks to align the amount of required collateral with the net market risk of the portfolio, as opposed to calculating margin requirements for individual positions. See Kenneth M. Rosenzweig, An Introduction to Portfolio Margining, 26 FUTURES \& DeRIVATIVES L. ReP. (Dec. 2006). As a practical 
sense, compression is more than simply a risk-reducing micro-level application: it is a system-level functionality for scaling up secondary markets in financial instruments.

To sum up, it is the system-wide operation of these four closely related transactional techniques (pooling, layering, acceleration, and compression) that empowers and sustains continuous quantitative growth and qualitative complexification of modern financial markets. These are also the enabling dynamics of what is routinely labeled "financial innovation." ${ }^{26}$ Much of that innovation is attributable to the iterative application of pooling, layering, acceleration, and compression tools in some new context or with the help of some new technology. ${ }^{127}$

\section{Systemic Implications of Secondary Market Proliferation}

Analyzing the process of continuous growth of the financial market through the lens of its core transactional modalities (pooling, layering, acceleration, and compression) allows us to draw several important conclusions about the nature of the financial system.

First of all, as a result of these mechanisms' combined operation, the financial system's macro-dynamics increasingly — and increasingly starklydiverge from the transactional micro-dynamics in the financial market. ${ }^{128}$ Moreover, the macro-level systemic factors play an increasingly important role in determining what happens in financial markets. In other words, focusing on transaction-level micro-factors - such as reducing counterparties' transaction costs, information asymmetries, and various other "frictions"-is less and less likely to shed any meaningful light on the behavior of the markets in which these transactions take place. To understand how markets behave, we must look to the broader modalities of those markets' self-regeneration and growth.

Recognizing how new financial assets and markets are continuously synthesized via pooling and layering, and then scaled up via acceleration and compression, helps us to visualize the logic of the system's ever-increasing structural complexity, internal interconnectedness, and fragility. The financial marketplace appears not as a flat space in which multiple parallel submarkets operate as largely independent and potentially competing "financial intermediation" platforms, but rather as a fractal universe driven by the unifying

matter, portfolio margining typically increases the level of leverage in the account. Id. This, in turn, enables significant scaling up of trading activity in the relevant market.

126. See supra notes 71-73 and accompanying text.

127. From this perspective, it becomes clear that the "innovative" nature of newly created financial products and market practices should not be confused with, or reduced to, their narrowly technical or micro-level transactional aspects. I plan to elaborate this important and complex point more fully as part of a separate research project.

supra note 21.

128. For a theoretical and historical analysis of these general dynamics, see Hockett, 
logic of self-replication. In this picture of the financial system, the most significant relational dynamics are not horizontal, as it is implicitly postulated in the "disintermediation" or "shadow banking" narratives, but vertical, as in the dynamic patterns of connecting the many layers of financial risk trading. ${ }^{129}$ And as this system grows bigger and moves faster, it also becomes increasingly unstable.

Another systemic implication of pooling, layering, acceleration, and compression is that they naturally operate to decrease the levels of transparency and governability of the financial market. It is difficult to "see through" the multiple layers of financial claims in a pyramid-like structure like a multi-layered fund of funds. It is even more difficult to assess the risks or to predict the behavior of a highly structured bespoke derivative referencing the value of other structured products. Similarly, the structural complexity and the speed of contagion in the financial market often render important market governance mechanisms, designed to resolve various market frictions, potentially ineffective. The failure of Lehman Brothers in October of 2008 provides an apt illustration of these trends. ${ }^{130}$

This example also highlights the third systemic implication of the current patterns of the growth of financial markets: an increasing importance and intensity of self-amplifying, or recursive, market-wide collective action problems and the resulting need for a more direct and effective exercise of market-wide collective agency. ${ }^{131}$

A structurally complex system based on the continuous synthesizing of tradable claims and scaling up trading activity is inherently prone to behaving procyclically. Investors in the fast-moving, contagion-prone, non-transparent financial markets are forced to act swiftly and in unison, whether that means not missing out on a "hot" investment or not being left holding the bag when it turns "toxic." 132 While individually rational, this behavior leads to collectively harmful results, as upward or downward price spirals become entirely divorced

129. For a full elaboration of this multi-layered architecture of the financial system, see Hockett \& Omarova, supra note 9.

130. See Michael J. Fleming \& Asani Sarkar, The Failure Resolution of Lehman Brothers, FED. RES. BANK OF N.Y. ECON. POL'Y REV. 175 (2014), https://www.newyorkfed.org/medialibrary/media/research/epr/2014/1412flem.pdf [https://perma.cc/A6B3-FCLK]. Thus, following the firm's bankruptcy filing, neither Lehman's own management nor its major trading counterparties were able to establish with certainty the value of its derivatives positions and resolve the problem through the "normal" governance mechanisms, thus necessitating government intervention. Id.

131. For an introduction and definition of the concept of "recursive collective action problem," or "ReCAP," and for an analysis of how this phenomenon manifests itself in a variety of contexts, see Robert Hockett, Recursive Collective Action Problems: The Structure of Procyclicality in Financial and Monetary Markets, Macroeconomics, and Formally Similar Contexts, 3 J. FIN. PERSP. 1 (2015).

132. See id. at 20-21. 
from so-called fundamental values. ${ }^{133}$ In a market where fundamental value is often hidden at the bottom of a long chain of increasingly virtualized representations of that value, these price spirals are bound to be more violent and destructive, which significantly raises the importance of being able to arrest them as quickly as possible.

In sum, today's financial market looks nothing like the early stock market model that inspired classic laissez faire theories. The market that keeps growing bigger, faster, more complex, and therefore more vulnerable to sudden and contagious shocks cannot rely on the "invisible hand" to steer it away from trouble. That market needs an effective counterweight to collectively disastrous asset price booms and busts: it needs a collective agent capable of acting not in pursuit of purely profit-making goals but in the collective interest of all market participants. ${ }^{134}$ While in theory this type of collective agency may be exercised by certain large private parties, the sheer scale of the modern financial market renders the private option impossible in practice. Only public actors, with their large size and unique risk tolerance, can realistically take on this critically important market-preserving role. ${ }^{135}$

As discussed above, under the terms of the New Deal settlement in finance, this market-preserving function has been explicitly assigned to the government, the quintessential collective agent in a modern polity. The government's role, however, was deliberately limited in order to leave control over capital allocation in private hands. ${ }^{136}$ Ironically, the very success of private actors in expanding their freedom to generate financial risks - via continuous synthesizing of tradable financial products and via scaling up of secondary market trading -is now gradually opening the crucial space for a much more direct and proactive public involvement in managing the flows of capital in financial markets. ${ }^{137}$

In this sense, the broad systemic implications of modern financial markets' modus operandi increasingly push against the basic premises of the New Deal settlement. In the New Deal paradigm, the government's principal role in financial markets is that of a regulator, an exogenous force with a clearly limited mandate to influence private actors' allocative decisions. ${ }^{138}$ Private market participants, by virtue of their presumed micro-informational advantages and individualized economic incentives (also presumed to be fundamentally aligned or align-able with the collective good), retain the ultimate control over allocating capital to specific economic uses. ${ }^{139}$ Yet, as the above discussion shows, these

\footnotetext{
133. Id.

134. See id. at 25.

135. For a full discussion of public instrumentalities' market-preserving functions, see Hockett \& Omarova, Public Actors, supra note 45, at 134-37.

136. See supra Section I.B.

137. See Hockett \& Omarova, Public Actors, supra note 45, at 140-44, 147-60.

138. See supra notes 44-47 and accompanying text.

139. See supra note 48 and accompanying text.
} 
presumptions do not necessarily hold in the context of increasingly complex, multilayered, self-referentially growing modern financial markets. The systematic prioritizing of micro-transactional factors over macro-systemic ones, built into the New Deal settlement, is quickly becoming an impediment to its continuing efficacy as the overarching market governance framework. ${ }^{140}$

The rise of fintech in recent years is likely to elevate these existing tensions to a qualitatively new level. Viewed in this context, fintech is emerging not merely as an exciting new way of making financial transactions faster and more convenient, but as a potentially powerful tool for resetting the current publicprivate balance in the financial system. ${ }^{141}$ While it is still too early to catalogue all of the specific ways in which the evolving technologies will or might be used to this effect, it is nevertheless both possible and necessary to begin a sustained inquiry into the macro-systemic aspects of key fintech trends.

\section{Decoding Fintech: Technological Revolution, Market Evolution, or Power Devolution?}

The arrival of fintech is often equated with a "revolution" in finance. ${ }^{142}$ Recent advances in digital communications, cryptography, data management, and machine learning promise to revolutionize financial transactions by making them infinitely faster, easier, cheaper, more secure, more widely accessible, and individually tailored to every user's needs. These claims and expectations also shape much of the public discussion on how fintech is "disrupting" financial markets and how it should therefore be regulated.

This Article argues that, in order to decode the meaning of "fintech revolution," we must analyze fintech not as a collection of discrete financerelated micro-transactional technologies, but as a macro-financial, systemic phenomenon. This requires, in turn, understanding whether, and how, specific fintech applications are going to affect (or are affecting) the public's capacity to maintain the stability of the macro-environment. On the one hand, fintech may present a unique opportunity to correct the structurally destabilizing imbalance between private generation and public accommodation of financial risk, built into the existing paradigm of financial regulation. On the other hand, it may

140. The recent growth of interest among the scholars of financial markets and regulation in understanding and adapting various insights from complexity studies and systems analysis reflects a growing recognition of the critical role of macro-systemic factors in finance. See, e.g., Robert F. Weber, Structural Regulation as Antidote to Complexity Capture, 49 AM. Bus. L.J. 643 (2012). While this is a promising avenue of analysis, it is important to keep in mind that, in contrast to many natural complex systems (such as the human body or a particular ecosystem), the financial system is socially and legally constructed. It is fundamentally a product of law, which is itself a product of explicit policy choices. Analyzing the financial market's intra-systemic qualities and functions, therefore, cannot be separated from the analysis of its normative and political determinants and implications.

141. See supra Section I.D.

142. See supra Section I.A. 
further intensify that imbalance, thus raising serious questions about the continuing viability of the New Deal settlement in finance. In this sense, the story of fintech is both that of the fundamental continuity and that of a qualitative change in the broad trajectory of modern finance.

This Part examines some of the more established fintech applicationsincluding cryptocurrencies, distributed ledger technology, marketplace lending, ICOs, and robo-advising - from this perspective. ${ }^{143}$ While not making any definitive claims, it highlights the degree to which these forms of fintech are poised to facilitate and amplify the preexisting systemic dynamics of finance, thereby further exacerbating the fundamental tensions built into the New Deal settlement.

\section{A. Eliminating Frictions: Cryptocurrencies and Distributed Ledgers}

To date, arguably the most promising and potentially impactful fintech applications have focused on resolving specific frictions in payments, clearing, and settlement of financial claims and transactions - the key functions performed by financial market infrastructures (FMI). ${ }^{144}$ Payments is an area of particular interest in this respect. This is partly the case because of the sheer ubiquity and systemic importance of the payment system. ${ }^{145}$ Partly, it is a result of recognizing persistent problems plaguing cross-border payments that typically involve several banks (which increases the costs of making payments) and take several days to clear the hurdles associated with currency conversions and various other regulatory and administrative issues. ${ }^{146}$ Fintech-driven solutions to the problem of slow and expensive payments range from the invention of alternative cryptocurrencies that aim to circumvent official sovereign currencybased payment channels to redesigning the payment platforms on the basis of some new digital technology.

\section{Bitcoin: Synthesizing Assets}

Bitcoin is the leading example of the first strategy. It is the most established and prominent cryptocurrency currently in use. ${ }^{147}$ In simple terms, Bitcoin is a

\footnotetext{
143. For a brief introductory description of these technologies, see $i d$.

144. See Federal Reserve Policy on Payment System Risk, FED. RES. 2 (2017), https://www.federalreserve.gov/paymentsystems/files/psr_policy.pdf [https://perma.cc/2AWM-525X].

145. Generally, a payment system is defined as "a set of instruments, procedures and rules for the transfer of funds between or among participants. Payment systems include, but are not limited to, large-value funds transfer systems, automated clearinghouse systems, check clearinghouses, and credit and debit card settlement systems." Id. at 6.

146. Id.

147. There is a rapidly growing body of popular and academic literature on Bitcoin and the blockchain technology underlying it. For a small sample, see PRIMAVERA DE FILIPPI \& AARON Wright, BlockChain AND the LAW (2018); NATHANiel PopPer, Digital Gold (2015); PAUl Vigna
} 
form of digital "cash," a decentralized virtual currency that operates through a network of peer-to-peer computers, or nodes. ${ }^{148}$ It is an online communication protocol that enables the use of bitcoins - electronic tokens or bits of data - as a means of payment and exchange similar to regular currencies. ${ }^{149}$ However, no sovereign backs Bitcoin, and no state or any single private institution controls its creation and use. ${ }^{150}$

At the heart of Bitcoin is an innovative blockchain technology, which allows verification and recording of each transaction within the system in a publicly distributed ledger. ${ }^{151}$ Encrypted transactions are solved by the nodes and grouped in blocks (every few minutes), which are recorded one after another in a chain. Each node in the system keeps a copy of the whole distributed ledger, which ensures that the entire record of transactions cannot be altered. ${ }^{152}$ Because of these features, Bitcoin users do not need to place trust in any single institution, like a bank or a securities broker, to keep the system secure. ${ }^{153}$ Bitcoins are stored in digital wallets, or data files that also contain recorded transactions and private keys necessary to spend or transfer bitcoins. ${ }^{154}$ The true identities of the transacting parties are hidden behind unique Bitcoin addresses. ${ }^{155}$ Bitcoin can be used to make payments and transfer value among digital wallet holders within that virtual system, which makes it a superior method of cross-border payments. ${ }^{156}$

Bitcoin is "mined" by solving the encrypted transactions that get added to the blockchain. The software, in effect, creates bitcoins and awards them to "miners" willing to expend their time and effort to verify encrypted transfers from one digital wallet to another. Mining Bitcoin requires significant computing power, and the difficulty of solving transaction "puzzles" is programmed to

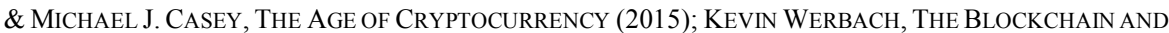
THE NEW ARCHITECTURE OF TRUST (2018).

148. See PEDRo Franco, UndERSTANDING BitCoIn: CRYPTOGRAPHy, ENGINEERING, AND ECONOMICS 4 (2015). Bitcoin was created in 2009 by Satoshi Nakamoto, which is believed to be a pseudonym for an unknown person or entity. Despite the mysterious nature of Bitcoin's creator(s), its current proponents maintain that open-sourced software cannot be controlled by its original creator and truly becomes a collective product that can only be altered by consensus arising in the community of peers. For a discussion of the intellectual origins and pre-history of Bitcoin, see id. at 161-69; and WERBACH, supra note 147, at 33-69.

149. Jose Pagliery, Bitcoin And the Future of Money 6 (2014). Bitcoin with a capital "B" typically refers to the entire system supporting the virtual currency, while "bitcoin" with a lower-case " $\mathrm{b}$ " denotes the actual unit of that currency. Id.

150. DE FILIPPI \& WRIGHT, supra note 147, at 21; FRANCO, supra note 148, at 3.

151. For a detailed treatment of blockchain and its operation, see DANIEL DRESCHER, BLOCKCHAIN BASICS: A NON-TECHNICAL INTRODUCTION IN 25 STEPS (2017).

152. FRANCO, supra note 148, at 15.

153. Id. at 8-9; WERBACH, supra note 147 , at 96-111.

154. Rainer Bohme et al., Bitcoin: Economics, Technology, and Governance, $29 \mathrm{~J}$. ECON. PERSP. 213, 220-21 (2015).

155. FRANCO, supra note 148 , at 9.

156. DE FILIPPI \& WRIGHT, supra note 147, at 20-22; 63-65. 
increase, in order to keep the supply of Bitcoin from rising too rapidly. ${ }^{157}$ Importantly, Bitcoin can also be bought and sold for U.S. dollars or any other sovereign currency. Several Bitcoin exchanges allow conversion of bitcoins into non-virtual currencies. ${ }^{158}$

To true Bitcoin enthusiasts, it represents a great vehicle of social good, which can broaden access to faster and cheaper money transfer and payment services for the poor and the unbanked around the globe. ${ }^{159}$ Libertarians embrace Bitcoin as an alternative to state-created conventional currencies and, more broadly, to the government monopoly on money and credit. ${ }^{160}$ And many techsavvy millennials prefer Bitcoin simply because it combines cost-saving efficiencies with greater privacy and security. ${ }^{161}$

For the majority of financial market participants, however, Bitcoin's main virtue is its value as an investment-or, more precisely, speculative investment - asset. ${ }^{162}$ As an asset, Bitcoin is extremely volatile. On July 19, 2010 , the recorded value of one bitcoin was just $\$ 0.06$. By December 16, 2017, the value of a single bitcoin reached $\$ 19,343.04 .{ }^{163}$ According to a respected industry publication, this puts the rate of Bitcoin's appreciation relative to the U.S. dollar in those seven years at $32,000,000 \% .{ }^{164}$ It is, therefore, not surprising that, while Bitcoin has not been able to displace sovereign currencies, it has successfully emerged as a brand new financial asset class. ${ }^{165}$

Importantly, Bitcoin's high volatility makes it an attractive underlying commodity for derivatives trading. ${ }^{166}$ In September 2014, TeraExchange

\footnotetext{
157. PAGLIERY, supra note 149 , at 33-34.

158. Bohme et al., supra note 154, at 220.

159. PAGLIERY, supra note 149, at 91-106.

160. Id. at 129-36. Not surprisingly, the debate on Bitcoin and other cryptocurrencies is frequently framed in terms of their role as an alternative form of money. This Article, however, intentionally shifts the focus toward cryptocurrencies' presently far more salient role as a new financial asset class. For an in-depth analysis of the complex dynamics of money-creation, see Hockett \& Omarova, supra note 9 .

161. PAGLIERY, supra note 149 , at 115-20.

162. See Rosa M. Lastra \& Jason Allen, Virtual Currencies in the Eurosystem: Challenges Ahead, ECON MONETARY DiAlogue STUDY 24 (July 2018), http://www.europarl.europa.eu/cmsdata/150541/DIW_FINAL\%20publication.pdf [https://perma.cc/E3QB-HYUD].

163. See Daniel Hinge, The Hunt for a Crypto Taxonomy, CENTRAL BANKING (May 4, 2018), https://www.centralbanking.com/central-banks/currency/digital-currencies/3494476/the-hunt-fora-crypto-taxonomy [https://perma.cc/TY2F-WDTK] (citing CoinDesk data).

164. Id.

165. For a more detailed analysis of these dynamics, see Hockett \& Omarova, supra note 9, at 1208-11. Of course, this does not deny the possibility of Bitcoin, or some other cryptocurrency, gaining broader circulation in commercial transactions in the future. See infra notes 171-172 and accompanying text.

166. The sheer magnitude of the Bitcoin speculative hype, especially in 2016-17, is staggering. Although in the first half of 2018 Bitcoin's market value came down significantly from its peak of nearly $\$ 20,000$ in late 2017 , it was still hovering around $\$ 10,000$ in May 2018. In his characteristically unsparing manner, Warren Buffett referred to Bitcoin as "rat poison squared," a less esthetically pleasing image than that of a tulip bulb. See Tae Kim, Warren Buffett Says Bitcoin is
} 
established the first regulator-approved U.S. bitcoin derivatives trading platform. ${ }^{167}$ In December 2017, the Chicago Mercantile Exchange (CME) and the Chicago Board Options Exchange (CBOE), the two largest and oldest U.S. commodity futures exchanges, raced to launch Bitcoin futures contracts. ${ }^{168}$ As the CME's website proclaimed, "Now you can hedge Bitcoin exposure or harness its performance with a futures product developed by the leading and largest derivatives marketplace: CME Group, where the world comes to manage risk." " 169 In May 2018, Goldman Sachs announced a decision to establish its own Bitcoin derivatives trading desk, in response to its institutional clients' growing interest in holding Bitcoin "as an alternate store of value" and to create "its own, more flexible version of a future, known as a non-deliverable forward." ${ }^{\prime 170}$ Later that same year, Intercontinental Exchange (ICE), a company that owns and operates New York Stock Exchange and various other exchanges and clearing houses, announced its plan to launch Bakkt, a new integrated platform for trading crypto-assets, starting with a physically delivered daily Bitcoin futures contract. ${ }^{171}$ A powerful financial market infrastructure conglomerate, ICE is undoubtedly well-situated to make Bakkt the first global "one-stop-shop" for trading, storing, and even spending digital assets for commercial purposes. ${ }^{172}$

"Probably Rat Poison Squared," CNBC (May 5, 2018), https://www.cnbc.com/2018/05/05/warrenbuffett-says-bitcoin-is-probably-rat-poison-squared.html [https://perma.cc/2BQN-EPCS].

167. See Michael J. Casey, TeraExchange Unveils First U.S.-Regulated Bitcoin Swaps Exchange, WALL ST. J. (Sept. 12, 2014), https://www.wsj.com/articles/teraexchange-launches-bitcoinderivatives-exchange-1410543989 [https://perma.cc/CA7J-XUGU].

168. See Dan DeFrancesco, FCMs Demand Self-Certification Overhaul After Bitcoin Debacle, RISK (Jan. 30, 2018), https://www.risk.net/commodities/5394306/fcms-demand-selfcertification-overhaul-after-bitcoin-debacle [https://perma.cc/MCN5-NLKK]. Both CME and CBOE listed their respective Bitcoin contracts through self-certification, which allowed them to avoid submitting the proposed contracts for regulatory approval. They were later criticized for the rushed and nontransparent nature of their actions, given the riskiness of these completely new products. $I d$.

169. CME GROUP, http://www.cmegroup.com/trading/bitcoin-futures.html [https://perma.cc/D3RT-TSAC].

170. Nathaniel Popper, Goldman Sachs to Open a Bitcoin Trading Operation, N.Y. TIMES (May 2, 2018), https://mobile.nytimes.com/2018/05/02/technology/bitcoin-goldman-sachs.html [https://perma.cc/QZ9H-FRM9]; Wolfie Zhao, Goldman Sachs to Begin Bitcoin Futures Trading, COINDESK (May 3, 2018), https://www.coindesk.com/goldman-sachs-to-begin-bitcoin-futures-tradingwithin-weeks [https://perma.cc/BHY5-C5FG].

171. See Bakkt Bitcoin (USD) Daily Future, INTERCONTINENTAL EXCH., https://www.theice.com/products/69281872/Bakkt-Bitcoin-USD-Daily-Future [https://perma.cc/5YB62KPM]. The physical delivery of crypto-assets underlying the futures is what sets Bakkt apart from the CME contracts that settle in sovereign currency. See Priyeshu Garg, World's 23rd Richest Man Invests in Cryptocurrency Exchange Bakkt's First Funding Round, CRYPTOSLATE (Jan. 8, 2019), https://cryptoslate.com/worlds-23rd-richest-man-invests-bakkt [https://perma.cc/6GLY-B44L].

172. See About Bakkt, BAKKT, https://www.bakkt.com/index [https://perma.cc/8LD5ASC5]. Notably, ICE's partners in the Bakkt venture include both Microsoft and Starbucks, whose customer base is the natural captive market for potentially massive commercial adoption of Bitcoin or any other cryptocurrency that Bakkt includes in its product offerings. See Sarah Whitten \& Kate Rooney, New Starbucks Partnership with Microsoft Allows Customers to Pay for Frappuccinos with Bitcoin, CNBC (Aug. 3, 2018), https://www.cnbc.com/2018/08/03/starbucks-partners-with-microsoft-ice-on-newcryptocurrency.html [https://perma.cc/8R2S-VREL]. It is somewhat ironic, of course, that technolibertarians' grand vision of Bitcoin as "democratic" money may finally come closer to becoming reality 
Turning Bitcoin into the raw material for derivatives trading has critically important systemic consequences. It legitimizes Bitcoin as a bona fide tradable financial asset, rather than merely a virtual token without any tangible value backing it, and incorporates it into the established financial market infrastructure. This instantly transforms the dynamics of Bitcoin trading by scaling up its volume and helping to support its price. In short, it makes Bitcoin - a digital token, or a bit of encrypted data - part of the same menu of financial assets as U.S. Treasury Bonds and shares in General Electric. ${ }^{173}$

Bitcoin's amazing journey from an obscure techno-utopian experiment to Goldman Sachs' market-making books and institutional investors' portfolios is also fascinating in a deeper sense. It provides a vivid example of how fintech technology can be, and is, used to synthesize tradable financial assets effectively out of thin air. In contrast to even the most esoteric traditional (that is, prefintech) financial products, the volume of tradable Bitcoin is not tied to, and thus constrained by, any financial claims issued in the primary markets for capital. The volume or value of Bitcoin bears no relation to the production of any actual goods or services in the nonfinancial economy. The supply of Bitcoin grows simply as a result of trading and transacting in Bitcoin. It is, in this sense, an entirely self-referential and self-reproducing secondary-market phenomenon. ${ }^{174}$

The growth of Bitcoin derivatives and potentially other Bitcoin-linked products (such as exchange-traded funds passively tracking bitcoin's value) is a classic example of pooling and layering, two of the core transactional techniques used to synthesize new tradable claims referencing a single underlying asset. The fact that, in this case, the underlying asset is a digital token, as opposed to shares in operating companies or barrels of oil, potentially removes any "natural" limits on the extent of such pooling and layering and, accordingly, on the ability of market participants to scale up trading in these continuously synthesized cryptoassets. ${ }^{175}$

\section{Distributed Ledger Technology: Scaling Up Trading}

In recent years, numerous financial institutions and fintech firms have been actively exploring a broader range of potential applications of the blockchain-

through the deliberate exploitation of urban dwellers' caffeine addiction by a small club of marketdominating corporations. If that were to happen, it would give the "Starbucks finance" metaphor a very different meaning. See supra note 106.

173. For a predictive analysis of this trend, see Hockett \& Omarova, supra note 9.

174. This, of course, runs directly contrary to the basic principles underlying modern monetary policy, where central banks continuously manage the money supply relative to the broader economy's productive capacity.

175. Although this discussion focused specifically on Bitcoin, it is important to remember that Bitcoin is merely the most advanced-stage representative of the vast and rapidly expanding universe of crypto-assets. 
or, more broadly, "distributed ledger"-technology underlying Bitcoin. ${ }^{176}$ Generally, distributed ledger technology (DLT) may be defined as "a set of technological solutions that enables a single, sequenced, standardized and cryptographically-secured record of activity to be safely distributed to, and acted upon by, a network of varied participants." ${ }^{\text {"177 }}$ It is important to note that DLT is not new or unique in its ability to allow multiple network participants to share and view data in near real time; it is simply another model within the familiar category of a "distributed database management system." 178 Yet, the blockchain mystique factor - the marketing power of the new fintech lexicon-has catapulted DLT into the very center of the financial sector's digital "innovation" efforts. ${ }^{179}$

Because DLT is said to be "asset-agnostic," in a sense of being able to provide "the storage, recordkeeping, and transfer of any asset," it can potentially be applied to optimizing a variety of processes, including not only payments but also post-trade clearing and settlement of any asset. ${ }^{180}$ So-called "smart contracts" that reside on distributed ledgers and distill contractual terms into a self-executing computer code can also be used for ongoing management of collateral and other counterparty obligations. ${ }^{181}$

Given the magnitude, the complexity of institutional arrangements, and the systemic significance of the payments, clearing, and settlement functions in wholesale financial markets, practical implementation of these concepts is no easy task. Not surprisingly, there are currently several parallel efforts to revolutionize these systems through adoption of DLT or "smart contracts." 182 These include, for example, the IBM-backed HyperLedger Fabric project that seeks to optimize cross-border trade financing and an open-source Corda

176. Technically, blockchain is merely a particular kind of DLT. For purposes of the present discussion, however, these differences are not especially relevant, and these terms will therefore be used interchangeably. See generally sources cited supra note 147.

177. FinanCIAl CONDUCT AUthority (UK), Discussion PAPER ON Distributed LEDGER TECHNOLOGY, DP17/3, 10 (Apr. 2017), https://www.fca.org.uk/publication/discussion/dp1703.pdf [https://perma.cc/27L6-HHFZ].

178. Id.

179. Id.

180. David Mills et al., Distributed Ledger Technology in Payments, Clearing, and Settlement 17 (Fed. Res. Bd., Fin. \& Econ. Disc. Paper No. 2016-095, 2016), https://www.federalreserve.gov/econresdata/feds/2016/files/2016095pap.pdf [https://perma.cc/NUM5NHU3].

181. See Luke Clancy \& Steve Marlin, Banks Test Promise of Blockchain as CCP Replacement, RISK (Dec. 22, 2015), https://www.risk.net/risk-management/2439561/banks-test-promiseblockchain-ccp-replacement [https://perma.cc/E24Y-V8XL]; see also, DE FILIPPI \& WRIGHT, supra note 147 , at 89-104 (discussing "smart" securities and derivatives).

182. For a reminder of what "smart contracts" are, see supra note 30 and accompanying text. 
platform for managing bank-to-bank financial agreements being developed by a large bank consortium, R3. ${ }^{183}$

In 2017, another consortium of major global banks, led by Switzerland's UBS, announced the next phase in the development of so-called "utility settlement coin," or USC. ${ }^{184}$ The USC is a digital currency stored on a permissioned blockchain and used by member banks to make payments to one another to clear and settle securities trades. This new cryptocurrency arrangement will allow for much faster and convenient clearing and settlement of bond and equity trades between the participating banks. ${ }^{185} \mathrm{In}$ each trade, both the bought-and-sold securities and the payment for them will be "delivered" through the consortium's blockchain system. Instead of using the relevant jurisdiction's official payment system and waiting for traditional money transfers to be completed, these banks will simply transfer the relevant amounts in USC to one another's USC accounts. The payee banks will then exchange their USC holdings for the relevant sovereign currency, on a one-to-one basis. ${ }^{186}$ This key feature of the proposed closed-universe, blockchain-based interbank payment platform-USC's direct convertibility into major sovereign currencies - requires an explicit commitment on the part of the relevant central banks to support the arrangement. ${ }^{187}$ The consortium reportedly approached several central banks - presumably, the Federal Reserve, European Central Bank, Bank of England, and Bank of Japan - to set up a system for guaranteed exchanges of USC for all major sovereign currencies. ${ }^{188}$

In early 2019, JPMorgan Chase \& Co., the \$2.6 trillion financial conglomerate, ${ }^{189}$ successfully tested its private blockchain-based digital coin, called JPM Coin. ${ }^{190}$ Pegged to the value of the U.S. dollar, JPM Coin is designed

183. See Hugh Harsono, Bank-Based Blockchain Projects Are Going to Transform the Financial Services Industry, TECHCRUNCH (Jan. 28. 2018), https://techcrunch.com/2018/01/28/bankbased-blockchain-projects-are-going-to-transform-the-financial-services-industry

[https://perma.cc/XQY9-B5F6]; Tanaya Macheel, R3 Makes Code for Financial Agreements Platform Open Source, AM. BANKER (Nov. 30, 2016), https://www.americanbanker.com/news/r3-makes-code-forfinancial-agreements-platform-open-source [https://perma.cc/2JTF-7555].

184. Michael del Castillo, Barclays, HSBC Join Settlement Coin as Bank Blockchain Test Enters New Phase, CoINDESK (Aug. 30, 2017), https://www.coindesk.com/hsbc-barclays-joinutility-settlement-coin-as-bank-blockchain-test-enters-final-phase [https://perma.cc/BLF2-SF5V].

185. Id.

186. See Izabella Kaminska, What Is 'Utility Settlement Coin' Really?, Fin. TIMES: ALPHAVILLE (Sept. 18, 2017), https://ftalphaville.ft.com/2017/09/18/2193542/what-is-utility-settlementcoin-really [https://perma.cc/PL3W-G9MK].

187. Id.

189. JPMorgan Chase \& Co., Annual Report (Form 10-K), at 1, https://jpmorganchaseco.gcs-web.com/static-files/cdb056f9-4973-4dc9-9319-e418b9ccf28f

[https://perma.cc/MK3K-S9EJ] (reporting that JPMorgan Chase held $\$ 2.6$ trillion in assets as of December 31, 2018).

190. See J.P. Morgan Creates Digital Coin for Payments, JPMorgan ChaSE \& Co. (Feb. 14, 2019), https://www.jpmorgan.com/global/news/digital-coin-payments [https://perma.cc/V998HXDF]. JPM Coin is run on JPMorgan's permissioned Quorum Blockchain, an enterprise version of 
to facilitate instantaneous payments and settlement of securities transactions among JPMorgan's institutional clients. ${ }^{191}$ The launch of the JPM Coin pilot elicited a great deal of excitement and support from the crypto-trading community, which viewed it as a significant milestone in the evolution of DLT and a sure sign of the "arrival of the institutional herd."192 JPMorgan's status as the country's largest diversified banking conglomerate-with its famed "fortress balance sheet" and direct access to public backing - is what gives DLT "a credibility boost in the eyes of industry peers, regulators and even consumers." 193 Even more to the point, the fact that JPMorgan Chase, N.A., the group's flagship banking entity, is a major global clearing and custody bank effectively guarantees high demand for JPM Coin among financial market participants. ${ }^{194} \mathrm{~A}$ massive roll-out of JPM Coin, in turn, is guaranteed to elevate JPMorgan, already a poster child for the controversial "too big to fail" phenomenon, to a qualitatively new level of systemic importance in the world's financial market infrastructure. ${ }^{195}$

The shortage of detailed information on big banks' private tokenization projects currently under way makes it difficult to understand how exactly these new DLT-based payments, clearing, and settlement arrangements will work in practice. ${ }^{196}$ It is even more difficult to identify and assess their potential impact-

Ethereum, with the future goal of making it operable across all Ethereum-based blockchain platforms. Id. For more on Ethereum, see infra notes 227-228 and accompanying text.

191. Id. In effect, JPMorgan is simply "tokenizing” its institutional clients' U.S. dollardenominated deposit balances. Importantly, the bank plans to extend its digital coin operations both to retail customer deposits and to deposits denominated in other sovereign currencies. Id.

192. Andrew Keys, J.P. Morgan Is Using Ethereum to Launch a 'Digital U.S. Dollar'-Here's What It Means for Blockchain, CONSENSYs (Feb. 14, 2019), https://media.consensys.net/j-p-morgan-is-using-ethereum-to-launch-a-digital-u-s-dollar-heres-what-itmeans-for-blockchain-64fofe3e55bc [https://perma.cc/QMZ8-F4DT].

193. Suleman Din \& Will Hernandez, List: 5 Things JPM Coin Will Do for Banking and Blockchain, AM. BANKER (Feb. 14, 2019), https://www.americanbanker.com/list/5-things-jpm-coinwill-do-for-banking-and-blockchain [https://perma.cc/ZSU4-49ZR].

194. See Penny Crosman, Can JPMorgan Chase's JPM Coin Knock Off Ripple and Swift?, AM. BANKER (Feb. 14, 2019), https://www.americanbanker.com/news/can-jpmorgan-chases-jpmcoin-knock-off-ripple-and-swift [https://perma.cc/HYF8-D99H] (stating that the 157 banks currently using JPMorgan Chase's payments network are expected to use JPM Coin for domestic and cross-border payments, while other banks may feel compelled to use it); Eleni Digalaki, JPMorgan Is Launching the First US Bank-Backed Digital Token, BUS. INSIDER (Feb. 19, 2019), https://www.businessinsider.com/jpmorgan-launching-jpm-coin-cryptocurrency-2019-2

[https://perma.cc/TN48-C7ST] ("The banking giant moves over \$6 trillion globally per day for companies, while its wholesale clients include $80 \%$ of all Fortune 500 corporations, giving JPM Coin a solid chance to see widespread adoption.").

195. For an in-depth analysis of the "too big to fail" phenomenon in finance, see Saule T. Omarova, The 'Too Big To Fail” Problem, 103 MinN. L. REV. (forthcoming 2019).

196. The design and operation of USC and JPM Coin are especially intriguing in this respect. See id. On the most basic level, both USC and JPM Coin are what is now known as "stablecoins": cryptoassets whose value is typically pegged to some sovereign currency, like the U.S. dollar. Stablecoins are designed to hold their value vis-à-vis sovereign money and, as a result, to serve as "safe" cryptoassets (effectively collateralized by sovereign money). See Matthew Leising, Love Crypto, But Not Its Volatility? Meet Stablecoins, BLoOMBerg (Jan. 27, 2019), https://www.bloomberg.com/news/articles/2019-01- 
both positive and negative — on the financial system's operation, resilience, and stability.

Generally, the most frequently cited potential benefits of using DLT for payments, clearing, and settlement include its ability to reduce complexity in cross-border transactions, improve "end-to-end processing speed and thus availability of assets and funds," increase "transparency and immutability in transaction record keeping," improve "network resilience through distributed data management," and reduce "operational and financial risks." ${ }^{197}$ In essence, DLT is expected to make trades settle pretty much instantaneously, thus significantly reducing transactional costs and counterparty risk. Some of the most widely cited potential risks of moving payments, clearing, and settlement functions onto DLT platforms include increased cyber-security and operational vulnerabilities, legal uncertainty with respect to ownership of digital tokens or enforceability of smart contracts, and (very importantly) finality of settlement in a distributed system not backed by a central bank. ${ }^{198}$ For most of these enumerated problems, though, there appear to be reasonably manageable solutions, some of which involve things like "more nimble" regulatory responses. ${ }^{199}$

From a systemic point of view, however, the prospect of widespread adoption of DLT-based systems for payments, clearing, and settlement of financial transactions may not be quite so favorably balanced. The main concern here is straightforward. If DLT succeeds in making wholesale payments, clearing, and settlement instantaneous, easy, and cheap, it will enable potentially exponential growth in the volume and velocity of trading in securities and other

27/love-crypto-but-not-its-volatility-meet-stablecoins-quicktake [https://perma.cc/K7AZ-WRA8]. Tether is one of the earliest and best-known stablecoins, but the list of these instruments is rapidly growing. See, e.g., THE StABLECOIN INDEX, https://stablecoinindex.com [https://perma.cc/T2G6-6NJA]. Despite the recent explosion in stablecoins' popularity, however, it is not clear to what extent they are actually "safe" and able to maintain their peg to central bank money. See Penny Crosman, N. Y. Regulators Have Approved Two Cryptocurrencies. Now What?, AM. BANKER (Sept. 11, 2018), https://www.americanbanker.com/news/ny-regulators-have-approved-two-cryptocurrencies-now-what [https://perma.cc/SC3E-HUV2]; Nikhilesh De, Stablecoins All Want to Be \$1, But They're Not Worth the Same, COINDESK (Oct. 16, 2018), https://www.coindesk.com/which-stablecoin-is-the-riskiest-thecrypto-market-is-pricing-that-in [https://perma.cc/E3MY-3TRV]. However, two closely related factors set JPM Coin and USC apart from most other stablecoins: (1) the fact that they are issued by publicly backed and regulated banks, which serves as an important guarantee of their stable value; and (2) their potential to reach (individually or collectively) the dominant position in cross-border wholesale securities clearing and settlement. See Ian Allison, R3 Rebuffed in Attempted Bid for Settlement Coin Blockchain Project, COINDESK (Sept. 5, 2018), https://www.coindesk.com/r3-rejected-utility-settlement-coinblockchain [https://perma.cc/T4WA-ZW63].

197. See Mills et al., supra note 180, at 17; COMM. ON PAYMENTS \& MKT. INFRASTRUCTURES, BANK FOR INT'L SETTLEMENTS, DistRIBUTED LEDGER TECHNOLOGY IN PAYMENT, Clearing AND SETTLEMENT 1 (Feb. 2017), https://www.bis.org/cpmi/publ/d157.pdf [https://perma.cc/K6H9-X4GP].

198. See Mills et al., supra note 180, at 28-29, 31-34.

199. "Regulatory sandboxes," which effectively exempt qualifying fintech firms from otherwise applicable regulations, are often presented as this kind of a nimble response. See generally Allen, supra note 7. 
financial assets. To put it simply, in a fully frictionless world of blockchainpowered transaction processing, overtly speculative trading will also be faster, easier, cheaper, and thus more voluminous.

Such system-wide scaling up of trading activity goes far beyond a mere improvement in end-to-end processing speed. Quantitative changes of this magnitude are bound to effect a qualitative change in the nature and behavior of financial markets more generally. This qualitative shift in market structure and dynamics will, in turn, magnify the systemic role of and amplify the pressure on central banks and other public instrumentalities charged with ensuring financial stability. Hyper-fast, hyper-expansive financial markets will require a hyper-fast and hyper-capacious public actor of "last resort." ${ }^{200}$ Envisioning the specific form or forms this collective agency should take is an exercise in bold institutional imagination, bound to raise a host of politically salient questions. ${ }^{201}$ Unless we are ready to face these questions, we are not ready for the arrival of frictionless trading in financial assets.

One more point is worth making in connection with DLT and its potential to revolutionize payments, clearing, and settlement infrastructure. Recall that the original Bitcoin payment system is designed to operate on the real-time gross settlement (RTGS) basis: each bitcoin transfer between wallets is assigned a unique identifier and, once added to the immutable public ledger, serves as an objective proof of the coin's ownership. In this "trustless" world, there is no built-in transactional credit function. No specialized intermediaries are lending their own balance sheets to transacting parties, and, therefore, there is no native netting capability.

This pure RTGS principle at the heart of the Bitcoin system-or, in terms of the market dynamics discussed above, acceleration without compression - is the main reason why public blockchain in its original form cannot support largescale trading in financial markets. Without the ability to net, counterparties' liquidity needs impose hard constraints on the volume of trading they can sustain. Furthermore, not only does the system have to process a great many more individual transactions, it also does not allow for trading on credit. Nor does it allow for using coins as collateral: a verified transfer effects a simple change in ownership recorded in the distributed ledger. Operationally, leverage becomes

200. For examples of what such a high-capacity public instrumentality might look like, see Hockett \& Omarova, Public Actors, supra note 45, at 140-74; Hockett \& Omarova, supra note 44; Omarova, supra note 61.

201. Among other things, it will directly implicate the recently reignited controversy over central bank powers and independence. For recent contributions to this debate, see PETER CONTIBROWN, THE POWER AND INDEPENDENCE OF THE FEDERAL RESERVE (2016); PAUL TUCKER, UNELECTED POWER (2018). 
far more difficult to use in a system that explicitly precludes "double-spending," or spending what you don't fully and exclusively own. ${ }^{202}$

It is this fundamental problem that the financial industry actors - the supposedly "disintermediated" banks and the "disruptive" nonbank challengers alike-are seeking to solve. Characteristically, both the problem and the solutions are couched in purely technological terms as a matter primarily of processing speed or computing power. Among the reported solutions is the Lightning Network, ${ }^{203}$ which allows people to sign smart contracts creating "time-locked, two-way payment channels" based on a pre-agreed notional amount and seeded with a single bitcoin payment. ${ }^{204}$ The parties can then transfer money to one another within that pre-set balance, as well as to and from third parties' accounts, forming "a network of traced payments that need not be confirmed in the Bitcoin blockchain." 205 By allowing limitless "off-chain" transactions managed via smart contracts, Lightning promises to overcome Bitcoin's processing capacity limits and to allow it to compete with Visa's network. ${ }^{206}$

These efforts, however, aim to deliver far more than simply a technical fix for a technical problem. Lightning and similar programs are potentially creating a crucial system-wide capacity for levering and netting of financial transactions "off chain." Now, what gets recorded in the publicly distributed ledger can simply be a net result of multiple trades run by dealers: a single ultimate number that provides precious little insight into market activity underlying it. In effect, this off-chain transacting replicates the familiar patterns of margin trading and collateralized borrowing that enable financial asset speculation. The new technology does not alter the economic substance, and public policy implications, of these transactional techniques: it is still all about private parties borrowing to make short-term profits in secondary market trading. But technology makes these old dynamics much less visible behind the shining veil of scientific progress. What used to be done "off balance sheet" can now be done "off blockchain," and with the same result: potentially excessive financial risk and leverage hidden behind an ostensibly transparent ledger. Yet, focusing on the form in which that publicly viewable but informationally incomplete ledger

202. To be clear, the absence of native netting and credit-extension capabilities presents a significant problem in the case of a non-permissioned, or truly distributed, ledger. Permissioned blockchain networks, such as JPMorgan's Quorum or the USC consortium's ledger, can be (and almost surely are) designed with embedded netting and credit-extension functionalities. See supra notes 184-195 and accompanying text.

69W4].

203. See Lightning NeTWORK, https://lightning.network [https://perma.cc/AR4B-

204. Michael J. Casey \& PaUl Vigna, The Truth Machine: The Blockchain AND THE FUTURE OF EVERYTHING 75 (2018).

205. Id.

206. Id. 
exists, whether it is a physical book or a complex piece of software, distracts attention from this basic fact.

\section{B. Democratizing Finance: Digital Crowdfunding and Robo-Advising}

In addition to its ability to optimize transaction processing and eliminate frictions in the operation of financial market infrastructures, fintech is often praised for its unprecedented potential to make financial markets more inclusive and equally accessible. ${ }^{207}$ Bitcoin, for example, is often touted as a tool of financial inclusion, because it makes payments and asset transfers more affordable. Two other fintech trends explicitly credited with this "democratizing" effect on financial markets are digital crowdfunding (including marketplace lending and ICOs) and robo-advising.

\section{Marketplace Lending and ICOs: Synthesizing Assets}

Crowdfunding is a loose category covering historically varied forms of finance. ${ }^{208}$ Today, crowdfunding generally refers to raising funds from a large number of individual investors, typically by using online social networks or specialized funding platforms. ${ }^{209}$ These platforms allow start-up companies and individual entrepreneurs to "market" their idea to a wide range of potential investors and, if successful, raise capital at a lower cost. ${ }^{210}$

207. See supra Section I.A. For a recent formulation of this approach to fintech as a potentially transformative force in promoting financial inclusion, see ALL. FOR FIN. INCLUSION, FINTECH FOR FINANCIAL INCLUSION: A FRAMEWORK FOR DIGITAL FINANCIAL TRANSFORMATION (Sept. 2018), https://www.afi-global.org/sites/default/files/publications/2018-

09/AFI_FinTech_Special\%20Report_AW_digital.pdf [https://perma.cc/9ESS-D2UX].

208. Crowdfunding is a form of crowdsourcing, a term that encompasses a broader variety of mass collaborations on a particular project or idea. Crowdsourcing often involves sharing of innovative ideas and soliciting of technical support, feedback, or other resources from the "crowd." Although not officially known as "crowdsourcing," the practice of gathering monetary or in-kind contributions from a dispersed group of people was widely used throughout history, most notably for various charitable purposes. See Craig R. Everett, Origins and Development of Credit-Based Crowdfunding (Working Paper, 2014), http://papers.ssrn.com/sol3/papers.cfm?abstract_id=2442897 [https://perma.cc/B2NZ-RJ44]. The advent of the internet enabled the rapid development of numerous peer-to-peer online transactional platforms (e.g., eBay and Napster) that led to the emergence of the current forms of online crowdfunding. See COGNIZANT, MARKETPLACE LENDING: A MATURING MARKET MEANS NEW PARTNER MODELS, Business OPPORTUNitIES 2 (July 2014), http://www.cognizant.com/InsightsWhitepapers/Marketplace-Lending-A-Maturing-Market-Means-

New-Partner-Models-Business-Opportunities-codex989.pdf [https://perma.cc/6C3P-MN3W]. In this Article, I use the term crowdfunding to refer solely to financial investment-oriented transactions, rather than philanthropically motivated loans or donations.

209. Joan MacLeod Heminway \& Shelden Ryan Hoffman, Proceed at Your Peril: Crowdfunding and the Securities Act of 1933, 78 TENN. L. REV. 879, 881 (2011).

210. For examples of online crowdfunding sites that provide a virtual marketplace for

prospective equity investors and capital-seeking entrepreneurs, see EQUITYNET, https://www.equitynet.com/how-it-works.aspx [https://perma.cc/D74D-KJ36]; $\quad$ FUNDABLE, https://www.fundable.com/landing/crowdfunding [https://perma.cc/JN3N-48V9]. 
Marketplace (a.k.a. peer-to-peer, or P2P) lending is simply crowdfunding of debt. It seeks to lower the costs of unsecured borrowing by eliminating the need for the services of a commercial bank or any other institutional lender. In the United States, online P2P lending got its official start in late 2005, when Prosper.com launched its online platform. ${ }^{211}$ Prosper.com and LendingClub, both of which focused initially on consolidation of consumer debt, quickly became the leading U.S. marketplace lending platforms. Their success spurred rapid growth of online lending platforms specializing in various loan products. ${ }^{212}$

Although individual lending platforms' operational models may differ, they generally share certain basic features. They typically cap the size and maturity of individual loans, limit individual investors' exposure to a particular borrower by breaking up the loan amount among a large number of investors, and use internal and external credit ratings to determine the risk-adjusted interest rate on each loan. The lending platform operators collect transaction and servicing fees. ${ }^{213}$ The basic idea is that, by using advanced technology to process information and underwrite loans quickly and at a low cost, marketplace lending sites are able to match individual lenders and borrowers efficiently and transparently. ${ }^{214}$

The proliferation of marketplace financing sites in the last decade led some observers to declare "possibly the beginning of a revolution in how the general public allocates capital." 215 Others welcomed it as a rising tide of ultimate "disintermediation." 216 However, the business quickly attracted sophisticated financial players able to conduct credit analysis and run risk models to tailor higher returns from their marketplace loan investments. Hedge funds, private equity funds, banks, insurance companies, and wealthy individuals became the primary buyers of marketplace loan products, ${ }^{217}$ which generally have higher

211. See PROSPER MARKETPLACE, INC., https://www.prosper.com
[https://perma.cc/V2C5-MLNE]. The model was pioneered in the United Kingdom by Zopa, which
launched the first peer-to-peer lending platform in 2005.
$212 . \quad$ RICHARDS KIBBE \& ORBE LLP, 2015 SURVEY OF U.S. MARKETPLACE LENDING
https://www.rkollp.com/assets/htmldocuments/RKO_LenderSurvey_FINAL2.pdf
[https://perma.cc/NUP2-ZXZ3].
213. See Renaud Laplanche, Five Big Myths About Marketplace Lending, AM. BANKER
(Jan. 28, 2015), https://www.americanbanker.com/opinion/five-big-myths-about-marketplace-lending
[https://perma.cc/9G3P-2MAZ].
214. Unlike banks, P2P platforms typically do not make loans using their own balance
sheets: they simply find individuals willing to lend money to a particular borrower at a particular rate. In
this model, even high-risk borrowers should be able to find potential lenders willing to take a small portion
of the risk, if compensated accordingly. Banks and other balance-sheet lenders don't have such flexibility.
215. C. Steven Bradford, Crowdfunding and the Federal Securities Laws, 2012 COLUM.
BUS. L. REV. 1, 5 (2012).
216. Andrew Verstein, The Misregulation of Person-to-Person Lending, 45 U.C. DAVIS
L. REV. 445, 449 (2011).
217. See Kevin Wack et al., Innovation of the Year: Online Marketplace Lending, AM.
BANKER (Dec. 17, 2014), https://www.americanbanker.com/news/innovation-of-the-year-online-
marketplace-lending [https://perma.cc/YDA6-YQ22]. Thus, investment management giant BlackRock


interest rates than traditional bank loans. ${ }^{218}$ Many of these investments are leveraged and subsequently securitized. ${ }^{219}$

The entry of yield-hungry institutional investors led to increased competition in the sector and pushed marketplace lenders to grow their loan origination volumes, diversify their loan products, and consolidate. ${ }^{220}$ Marketplace lenders now routinely form partnerships with banks and other institutional investors, pursuant to which banks and other investors commit to buying a certain percentage of whole loans originated by or through the marketplace platform. ${ }^{221}$ To satisfy institutional investors' demand for this lucrative asset class, marketplace lenders intensified their borrower-acquisition efforts, partly by extending more high-risk loans. ${ }^{222}$

In short, within a decade, marketplace lending has effectively evolved from an alternative form of peer-to-peer finance into a post-crisis rendition of subprime lending and shadow-banking securitization. ${ }^{223}$ In this sense, it functions as a classic channel of continuous synthesizing of tradable assets used to construct multi-layered and interconnected chains of financial claims. Rather than reinventing credit as a truly decentralized and democratic means of mutual self-help, today's marketplace lending operates primarily as a means of scaling up trading volumes in institutionally dominated wholesale markets. ${ }^{224}$

By 2017, the tech-savvy public's attention had shifted to a new form of digital crowdfunding: "initial coin offerings," or ICOs. In an ICO, a firm

heavily invested in marketplace lending, while George Soros and former PIMCO CEO Mohamed El-Erian were among the high-profile individual investors. $I d$.

218. For example, LendingClub has delivered an adjusted annualized return of nearly $8.7 \%$ on the first $\$ 8$ billion of issued loans and has issued over $\$ 1$ billion in personal loans carrying interest rates above 20\%. Todd Baker, Marketplace Lenders Are a Systemic Risk, AM. BANKER (Aug. 17, 2015), https://www.americanbanker.com/opinion/marketplace-lenders-are-a-systemic-risk

[https://perma.cc/RGV8-4RDM]. In 2014, OnDeck, a marketplace platform specializing in small business lending, reportedly issued loans at an average annual percentage rate of $54 \%$. Kenneth A. Posner, Alternative Lenders Have a Ways to Go to Ensure “Revolution," AM. BANKER (Jan. 12, 2015), https://www.americanbanker.com/opinion/alternative-lenders-have-a-ways-to-go-to-ensure-revolution [https://perma.cc/SZ64-NAVB].

219. See Kevin Wack et al., supra note 217.

220. See Kevin Wack, Shakeout Is Coming, Marketplace Lenders Warn, AM. BANKER

(Apr. 16, 2015).

221. See Kevin Wack et al., supra note 217; Mike Cagney, How Marketplace Lenders Will Save Financial Services, AM. BANKER (Aug. 19, 2015), https://www.americanbanker.com/opinion/how-marketplace-lenders-will-save-financial-services [https://perma.cc/XSW9-3YP7].

222. See Baker, supra note 218.

223. See Hockett \& Omarova, supra note 9, at 1207.

224. In June 2018, SoFi's CEO announced the company's new strategy of making loan decisions, funds disbursements, and securitizations instant. Penny Crosman, SoFi's CEO Strategy for Success: "Make Every Transaction Faster," AM. BANKER (June 20, 2018), https:/www.americanbanker.com/news/sofi-ceos-strategy-for-success-make-every-transaction-faster [https://perma.cc/XPW4-WZFX]. This aptly underscores the significant potential of marketplace lending as a broad-based platform for the continuous synthesizing of high-yield assets and scaling up of secondary market trading. 
planning to develop and produce some form of a digital product (e.g., new software) sells project-specific digital tokens that can be used as units of currency in purchaser's hands once the project launches. ${ }^{225}$ Depending on the scheme, these tokens may be used for different purposes: some of them simply allow access to an online platform or grant participation and governance rights in a particular online network, others can be used to buy the product or service being funded, and yet others may entitle their holders to an actual portion of profits from the project in question. ${ }^{226}$ The vast majority of ICOs to date are done using smart contracts on the Ethereum platform. ${ }^{227}$ The key advantage of using Ethereum is that its technology allows for smooth post-ICO trading of the tokens: i.e., it enables the emergence of a secondary market in these new digital "assets." 228

In 2014, Ethereum itself became one of the first examples of a successful ICO by raising about $\$ 18.4$ million through pre-sales of ether, its native cryptocurrency. ${ }^{229}$ As the popularity and use of Ethereum as the platform of choice for various crypto-projects grew, the value of ether increased correspondingly, making it a valuable financial investment. ${ }^{230}$ ICOs went mainstream in 2017, which saw hundreds of offerings raise billions of dollars. ${ }^{231}$ Notably, the most successful ICOs of the year included ventures promising to improve the existing blockchain infrastructure, to offer a "better" cryptocurrency, or to make existing crypto-assets easier to monetize. ${ }^{232}$

\footnotetext{
225. See supra note 33 and accompanying text.

226. See Wilson SONSINI GOODRICH \& ROSATI, INITIAL COIN OFFERINGS: AN OVERVIEW OF REGULATORY CONSIDERATIONS (June https://www.jdsupra.com/legalnews/initial-coin-offerings-an-overview-of-98251 [https://perma.cc/236X-LZN7].

227. See CASEY \& VIGNA, supra note 204, at 99. Ethereum is designed as a common platform for hosting an infinite variety of so-called "decentralized apps" (or "Dapps") for cryptographically recording and exchanging all manner of digitized data: medical records, land titles, titles to goods, marriage certificates, copyright and other rights, contractual payments, etc. Computers verifying transactions earn ether, Ethereum's cryptocurrency, whose value accordingly increases as the network grows. Ethereum's internal programming language allows third parties to write an unlimited variety of programs, thus enabling an unlimited variety of "smart contracts." Id. at 79-81.

228. Ethereum's standardized set of smart-contract instructions allows various digital tokens to retain a common, consistent format allowing these tokens to be traded on top of Ethereum's blockchain even after the conclusion of an ICO. Id. at 102.

229. Id. at 84,99 .

230. Id.

231. According to some estimates, the total amount raised in ICOs in 2017 exceeded $\$ 5.6$ billion. Oscar Williams-Grut, Only 48\% of ICOs Were Successful Last Year But Startups Still Managed to Raise \$5.6 Billion, BuS. INSIDER (Jan. 31, 2018), http://www.businessinsider.com/howmuch-raised-icos-2017-tokendata-2017-2018-1 [https://perma.cc/NP44-M6EU].

232. Oscar Williams-Grut, The 11 Biggest ICO Fundraises of 2017, BUS. INSIDER (Jan. [https://perma.cc/8DU6-UE6P]. The biggest ICO of 2017 was Filecoin, which raised about $\$ 257$ million from sales of a token entitling its holders to blockchain-based data storage space. Id. Perhaps the most interesting case from the perspective of this Article was the SALT Lending Platform ICO, with the tokens
} 
To fintech enthusiasts, ICOs signal a profoundly democratic shift in market power from traditional venture capital firms to users of the relevant digital product or service. ${ }^{233}$ Yet, it is undeniable that ICOs are often seen as purely speculative financial plays. ${ }^{234}$ Throughout 2017, investors were ready to snap up ICO "assets," often in a matter of minutes, without much due diligence conducted in traditional securities offerings. ${ }^{235}$ They didn't appear to worry about whether or not the tokens they were buying were related to an economically viable enterprise, or to any economic activity outside the cryptoasset space. ${ }^{236}$ Undiscriminating investor demand for tradable tokens drove inflated ICO valuations, a familiar sign of a speculative asset boom. ${ }^{237}$

Predictably, surging ICOs raised alarm among financial regulators concerned with investor fraud and criminally connected fundraising. ${ }^{238}$ From a systemic perspective, however, ICOs implicate a far more structurally significant shift. Complete virtualization of tradable assets enables - at least in principle, but very likely in practice as well-a virtually complete separation of the financial system from the real economy. Free of any "natural" productivityrelated constraints, financial markets will easily morph into sites of pure cryptospeculation. Left unconstrained, this continuous generation of tradable bits of encrypted data will easily transcend the limits of traditional systemic stability regulation, leaving both the financial system and the real economy vulnerable to shocks originating in an increasingly self-referential crypto-space. It will also render regulators' task of protecting investors and capital markets from abuse and misconduct inherently impossible to perform via traditional means.

\footnotetext{
designed to allow holders of cryptocurrencies to use them as collateral for borrowing in fiat currencies. Id.

233. See Richard Waters, To Coin a Craze: Silicon Valley's Cryptocurrency Boom, Fin. TiMES (Sept. 13, 2017), https://www.ft.com/content/2b0d8926-96d9-11e7-b83c-9588e51488a0 [https://perma.cc/P2U8-XHUC].

234. Id.

235. See CASEY \& VIGNA, supra note 204, at 103-04 (citing to an ICO by Gnosis, whose platform allows users to create prediction markets for betting on anything, in which the company raised $\$ 12.5$ million in twelve minutes).

236. See Waters, supra note 233.

237. Id. Even high post-ICO failure rates did not dampen this speculative demand. See Aaron Hankin, Nearly Half of All 2017 ICOs Failed, MARKETWATCH (Feb. 26, 2018), https://www.marketwatch.com/story/nearly-half-of-all-2017-icos-have-failed-2018-02-26 [https://perma.cc/88PG-9C4J].

238. For example, China and South Korea banned ICOs in 2017. See Darryn Pollock, From Gibraltar to Australia: How Countries Approach ICOs, CoINTELEGRAPH (Feb. 16, 2018), https://cointelegraph.com/news/from-gibraltar-to-australia-how-countries-approach-icos

[https://perma.cc/6H5L-8GXE]. In the United States, the SEC announced that certain ICOs may constitute securities issuances subject to federal securities laws. See Spotlight on Initial Coin Offerings, SEC, https://www.sec.gov/ICO [https://perma.cc/6VPL-CTVT]. In 2018, the SEC brought several enforcement actions against crypto-token issuers. See Will Hernandez, Blockchain Startup Inches Closer to Legally Tradable Tokens, AM. BANKER (Dec. 21, 2018), https://www.americanbanker.com/news/blockchainstartup-inches-closer-to-legally-tradable-tokens [https://perma.cc/KR8R-ANAK].
} 


\section{Robo-Advising: Scaling Up Trading}

Robo-advisors are "automated interfaces that offer investment advice and discretionary investment management services without an intervention of a human advisor, using algorithms and asset allocation models that are advertised as being tailored to each individual's investment needs." 239 Robo-advising is quickly becoming a mainstream financial service. Charles Schwab, Vanguard, and Fidelity offer robo-advising services. ${ }^{240}$ Even Morgan Stanley, one of Wall Street's most venerable investment banks, launched a robo-advising unit in December 2017. ${ }^{241}$

Because robo-advisors eliminate expensive human labor and use algorithmic trading to maintain or adjust clients' portfolio allocations, their services are significantly cheaper than those of traditional wealth managers. ${ }^{242}$ Robo-advisors are potentially able to offer relatively simple and cost-effective investment options - mainly, index mutual funds and passive exchange-traded funds - to a wider array of clients. ${ }^{243}$ The absence of human intervention is also touted as an attractive feature of robo-advising because it promises to eliminate potential conflicts of interest plaguing the fund management industry. ${ }^{244}$ For these reasons, proponents of robo-advising routinely portray it as a valuable tool of financial inclusion and "democratizing" wealth management by broadening its availability beyond the exclusive world of wealthy people. ${ }^{245}$ Critics, on the other hand, contest these claims as significantly overstating the cost-efficiency and integrity of robo-advice and warn against channeling retirement and retail investors' money into these automated accounts. ${ }^{246}$

It is hardly surprising that the continuing growth of robo-advising invites debate. Replacing humans with algorithms in an area traditionally based on

239. Chiu, supra note 5, at 88 . Robo-advisors rely on online questionnaires, filled out by prospective clients, to devise asset allocation and trading strategies that most closely track each client's expressed investment goals, preferences, and general risk parameters.

240. See Matthew Frankel, Robo-Advisers: What They Cost and What You Get, MotLEy Fool (Nov. 13, 2017), https://www.fool.com/retirement/2017/11/13/robo-advisors-what-theycost-and-what-you-get.aspx [https://perma.cc/NSA3-Z72K]. Charles Schwab and Vanguard are, of course, already well known as pioneers in democratizing access to wealth management.

241. Maria Terekhova, Morgan Stanley Launches a Robo-Adviser After 6 Month Pilot, BUS. INSIDER (Dec. 5, 2017), http://www.businessinsider.com/morgan-stanley-launches-a-robo-advisorafter-16-month-pilot-2017-12 [https://perma.cc/B5TK-AL22].

242. Chiu, supra note 5, at 89.

243. Id.

244. Baker \& Dellaert, supra note 6, at 726. For an easily accessible and comprehensive account of pervasive agency problems in the mutual fund industry, see WILLIAM A. BIRDTHISTLE, EMPIRE OF THE FUND: THE WAY WE SAVE NOW (2016).

245. See Robo-Advisors: Capitalizing on a Growing Opportunity, DeloITte (2015), https://www2.deloitte.com/content/dam/Deloitte/us/Documents/strategy/us-cons-robo-advisors.pdf [https://perma.cc/72R8-A8C8].

246. See, e.g., Melanie Fein, Robo-Advisers: A Closer Look (Working Paper, 2015), https://papers.ssrn.com/sol3/papers.cfm?abstract_id=2658701 [https://perma.cc/Y44X-PVZW]. 
relationships and exercise of professional judgment by trusted fiduciaries is not simply a matter of lowering fees. ${ }^{247}$ It raises a host of important legal and regulatory issues, especially with respect to advisors' fiduciary duties and investor protection under securities laws. ${ }^{248}$ These issues, however, are beyond the scope of this Article. For present purposes, it is critical to focus on the broader potential systemic significance of robo-advising.

One important factor in this respect is that the lower cost - and thus broader accessibility - of robo-advising is not simply a result of eliminating the expense of hiring a human expert. This cost efficiency is also a product of passive indextracking strategies typically pursued by robo-advisers. Robo-advice tends to channel clients' money into ETFs and other passive investments, often also determined by algorithms, which are inherently cheaper than actively managed fund products. ${ }^{249}$

In this sense, robo-advising appears to amplify both fundamental patterns of secondary market growth, discussed above: it enables synthesizing of new tradable assets, and it serves to scale up the aggregate trading activity in financial markets. ${ }^{250}$ Reaching significant segments of the population previously unable to participate in capital markets potentially improves ordinary people's access to investment opportunities. At least as importantly, however, it also improves the market's "access" to their savings. ${ }^{251}$ Through robo-advising, new market entrants' money is used to create new financial products that can then be pooled and layered, potentially many times over. This constant influx of new "base" products is critical for sustaining the financial market's built-in tendency to keep scaling up.

Furthermore, as discussed above, the central role of algorithmic trading in the robo-advising business model has a direct - and potentially massiveacceleration effect on financial asset trading. ${ }^{252}$ The fact that, in generating all of this additional trading activity, robo-advisers tend to use similar algorithms

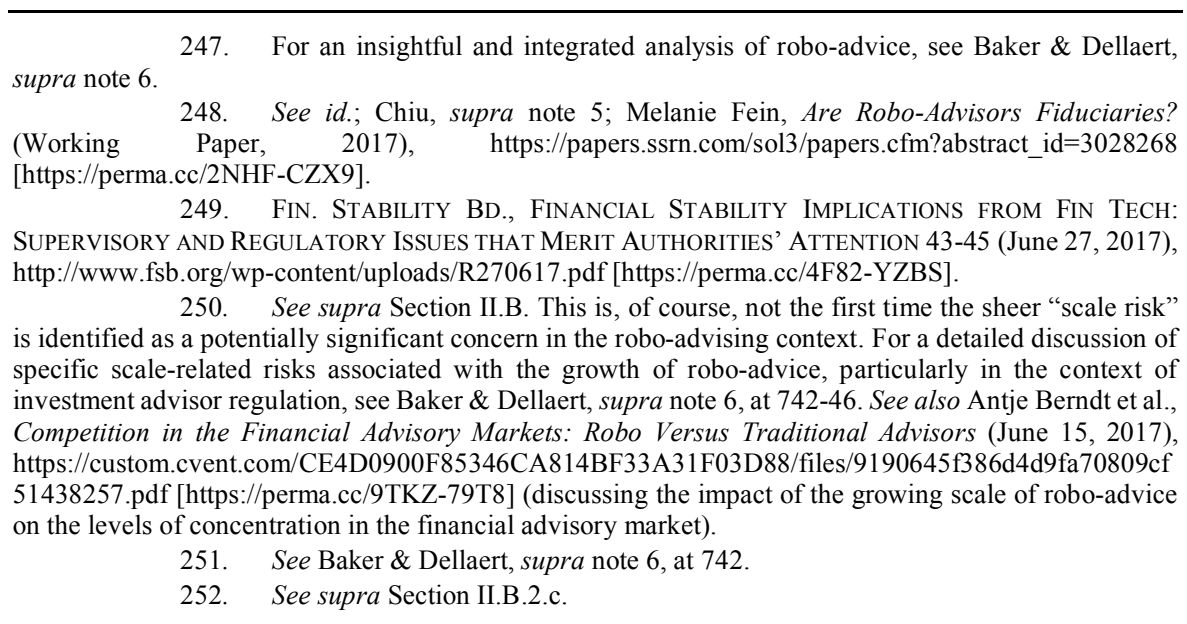


raises serious stability-related concerns about potential herding behavior and the possibility of rapid unidirectional portfolio shifts. ${ }^{253}$ Not only are there many more super-fast trades being executed via robo-advisors' algorithms, these trades are likely to form potentially highly correlated tidal waves of money moving in and out of the same asset classes. ${ }^{254}$

In fact, there are serious reasons to believe that the real driver behind the rapidly rising popularity of robo-advising is not the commonly touted "democratizing" impulse but the growing appeal of algorithmic trading as a portfolio-enhancing strategy for wealthy investors. Thus, it appears that roboadvisors are increasingly targeting wealthy (or relatively wealthy) investors who are already in the market, rather than the truly "under-served" low-income people. ${ }^{255}$ Many large robo-advisors are introducing minimum account balance requirements for access to digital investment services, ranging from $\$ 25,000$ to $\$ 50,000$ and possibly higher. ${ }^{256}$ For this contingent of wealthy investors, roboservices are a source of new, cost-efficient portfolio diversification opportunities. In line with the same logic, Morgan Stanley's robo-advising unit is said to target primarily the millennial children of the bank's existing clients. ${ }^{257}$

Tellingly, there are stark parallels between these developments and the dynamics in marketplace lending, discussed above. There, what started as a promise of a peer-to-peer credit system quickly evolved into another rendition of the institution-dominated market for high-yield consumer debt. ${ }^{258}$ Here, what started as a promise of opening the world of investment to the poor is quickly evolving into the reality of opening the world of (yet more) speculative trading to the wealthy.

As these examples demonstrate, technology alone cannot make the financial system more "democratic" or "just." Democratizing finance cannot be reduced to a purely technical exercise in decentralizing financial services or making them cheaper through the use of algorithms. It is an inherently political exercise, and only a democratic polity can achieve that goal through a coherent

\footnotetext{
253. FIN. STABILITY BD., supra note 249, at 45-46.

254. Id.

255. See Bryan Yurcan \& Suleman Din, Will Cheap Advice Turn Off Wealthy Clients?, AM. BANKER (June 5, 2018), https://www.americanbanker.com/news/fifth-third-securities-and-fidelitypartner-on-automated-advice-for-small-investors [https://perma.cc/A89M-EC3N] (discussing how large financial institutions' robo-advising services target the "mass affluent audience").

256. Id. ("Wells Fargo and U.S. Bank have digital advice account minimums double that of Fifth Third's. And by blending human service with digital platforms, other firms have sought wealthier clients. Schwab's Intelligent Advisory service has a $\$ 25,000$ account minimum, while Vanguard's Personal Advisor Services (the largest digital advice platform, with over $\$ 100$ billion in assets under management) has a $\$ 50,000$ account minimum.”).

257. See Terekhova, supra note 241.

258. See supra Section III.B.1.
} 
and comprehensive program of institutional reforms. ${ }^{259}$ The real question is whether the exciting new technology will be used to aid or to impede this process.

\section{Fintech as a Systemic Phenomenon: Unsettling the Public-Private Balance}

This brief overview of certain key developments in the rapidly evolving fintech sector is not meant to be an exhaustive catalogue of everything that this sector has to offer. Nor does it claim to present a full analysis of specific legal, technical, and policy issues these developments raise. ${ }^{260}$ Instead, the purpose of the present discussion is to trace the fundamental continuity behind the fintech "disruption," in search of a new conceptual and normative perspective for understanding fintech as a systemic phenomenon.

Standard accounts of the systemic implications of fintech activities tend to present lengthy sets of fintech-related factors that are likely either to reduce various systemic risks or to amplify them. Some of the commonly listed financial stability enhancers include, for example, systemic risk-reducing effects of making transacting faster and easier (i.e., eliminating market "frictions") and greater competition in the financial services industry. ${ }^{261}$ Potential systemic risk amplifiers, on the other hand, include the heightened tendency toward herding behavior and procyclicality, greater vulnerability to technical glitches and operational failures, and the rise of the systemic importance of non-financial firms. $^{262}$

Although these are valid and serious arguments worthy of attention and study, the focus of this Article is on the deeper-and broader - dynamics within the financial system. As argued above, the New Deal political settlement established the fundamental balance of public and private roles, competencies, and responsibilities in the financial sphere. ${ }^{263}$ Under its terms, private market participants are primarily in control of allocating financial capital, while the

259. For a comprehensive theoretical and practical analysis and justification of, and specific proposals for implementing, such institutional reform, see, for example, Hockett \& Omarova, Public Actors, supra note 45; and Hockett \& Omarova, supra note 44.

260. For recent analyses of these issues, see sources cited supra notes 4-5.

261. See Fin. STABILITY BD., supra note 249, at 16-17.

262. Id. at 20-21. Overall, however, the currently prevailing attitude among regulators appears to be that, due to their relatively small scale, the emerging markets for crypto-assets pose no appreciable threat to systemic financial stability. For recent official statements to that effect, see, for example, Eur. SeCS. \& MKTS. Auth., AdViCE: Initial CoIN OfFERINGS AND CRYPTO-Assets 17 (Jan. 9, 2019), https://www.esma.europa.eu/sites/default/files/library/esma50-157-1391 crypto advice.pdf [https://perma.cc/7BPB-7RV9]; EUR. BANKING AUth., REPORT WITH ADVICE FOR THE EUROPEAN $\begin{array}{llllll}\text { COMMISSION ON } & \text { CRYPTO-ASSETS } & 4 & \text { (Jan. } & 9, & \text { 2019), }\end{array}$ https://eba.europa.eu/documents/10180/2545547/EBA+Report+on+crypto+assets.pdf [https://perma.cc/Z4T9-STLQ]. See also U.K CRYPTOASSETS TASKFORCE, supra note 4, at 38-39. As the preceding discussion shows, this reasoning reflects a fundamentally incomplete understanding of the true systemic "scale effects" of fintech.

263. See supra Section I.B. 
sovereign public is primarily responsible for maintaining macro-financial stability. ${ }^{264}$ From this perspective, the emerging fintech technologies and activities are not merely recreating some of the familiar sources of systemic risk or rearranging the familiar institutional landscape of financial services. At the higher level of magnitude, fintech's systemic impact has to be assessed in terms of its potential to cause a decisive shift in the currently existing public-private balance in finance.

While it is difficult to generalize across the evolving and varied fintech space, the new technologies' self-proclaimed unifying raison d'être is qualitative transformation and optimization of transactional capacity in financial markets. Importantly, that refers primarily, if not exclusively, to private transacting capacity. ${ }^{265}$ In some instances, this goal of directly empowering the private, as opposed to the public, side of the financial market is quite explicit. Bitcoin enthusiasts, for example, openly tout that cryptocurrency's ambition and ability to do away with sovereign governments' control over money. ${ }^{266}$ In most instances, however, the rhetoric of fintech consciously emphasizes its potential to yield significant public benefits: financial inclusion, greater financial autonomy, and greater convenience, among other things. ${ }^{267}$

Yet, even a brief examination of these new technologies reveals the sense in which they systematically tip the scale in favor of the private, as opposed to the public, side of the New Deal settlement. By making transacting in financial markets infinitely faster, cheaper, and easier to accomplish, fintech critically augments the ability of private actors to synthesize tradable financial claims - or private liabilities - and thus generate new financial risks on an unprecedented scale. Moreover, as the discussion of Bitcoin and ICOs shows, new cryptotechnology enables private firms to synthesize tradable financial assets effectively out of thin air. ${ }^{268}$ This may be thought of as the crucial last step in the decades-long process of virtualization of financial claims - e.g., through creation of derivatives and other highly structured financial products - which will finally render financial markets entirely self-referential. ${ }^{269}$

It is difficult to overestimate the significance of this leap for the financial and economic systems. Making financial trading explicitly divorced from the

264. Id.

265. This is, of course, natural, given that most fintech applications are being developed by profit-seeking private market participants. Governments may and do participate in fintech projects, especially as they explore the potential for issuing sovereign cryptocurrencies, but they have not yet commandeered any particular technology for principally public use.

266. See Lastra \& Allen, supra note 162, at 18-20.

267. Id.; see also TREASURY REPORT, supra note 4, at 17.

268. See supra Section III.A.1.

269. It is also worth noting that, on a deeper normative level, the increasing emphasis on the speed of transacting may further undermine the value of patience - and thus patient capital -in finance, which is bound to have significant macro-economic implications. For a discussion of "patient capital" as a form of publicly salient good and as a necessary condition for stable and sustainable longterm macroeconomic development, see Hockett \& Omarova, supra note 44, at 450-51. 
production of any actual goods or services in the real, or non-financial, economy will have enormous consequences both for financing and organizing the entire economic system and for managing the financial sector.

Among other things, it will make it increasingly difficult, if not impossible, for the sovereign public to continue safeguarding and guaranteeing macrofinancial stability. The sheer scale and complexity of the financial market effectively "liberated" from exogenously imposed constraints on its growth will make it inherently more volatile and unstable - and, consequently, both far more dependent on public support and requiring far greater quantities of such support. The same factors, however, will also make it increasingly difficult, if not impossible, for the public to control, or even track, new technology-driven proliferation of risk in the financial system. Moreover, the underlying policy rationale for the public accommodation of privately created financial liabilities - namely, the publicly salient role of financial markets in channeling investments in the real economy-will effectively disappear. In short, in this new environment, the public will be forced to bear a vastly greater (and difficult to quantify in advance) burden of stabilizing an increasingly unstable and uncontrollable financial system that keeps growing for the sake of its own growth.

The key point here is not to assert the inevitability of this, or any other, specific scenario. My purpose is to show why fintech as a systemic phenomenon cannot be reduced to a mere collection of specific transactional friction-solving tools. Fintech has to be appreciated for its potentially game-changing effect on the existing balance of public and private power to define the fundamental purpose and direction of the financial system. Even at this early stage, it is increasingly apparent that various forms of "disruptive" fintech technologies, in fact, operate in tandem with and amplify the same long-standing financial market dynamics - pooling and layering of financial assets and acceleration and compression of financial transactions - that have been gradually eroding the New Deal settlement. If (or when?) fintech delivers on its promise to make these mechanisms virtually frictionless, thus taking their operation to a qualitatively different level, the financial market will completely forsake the frail confines of the New Deal settlement. We need to start thinking seriously about what should replace it. In this sense, fintech is ultimately a matter of public policy of the highest order.

Conclusion

Fintech is visibly "disrupting" traditional methods of delivering financial services and conducting financial transactions. Less visibly, it is also changing the way we think about finance and envision its future trajectory. The rise of fintech is gradually recasting our collective understanding of the financial system in seemingly objective (science-driven and normatively neutral) terms, as simply another sphere of applying advanced information technologies and computing 
power to eliminate specific transactional "frictions" in financial markets. By making transacting faster, easier, cheaper, and instantly adjustable to individual parties' needs and preferences, new technology seems to promise a "win-win" solution to the financial system's many ills.

This Article has presented an alternative account of fintech as a systemic, as opposed to merely transactional, phenomenon. Grounding the evolving fintech trends in the broader institutional context of the financial markets' operation, the Article exposed the normative and political significance of the current fintech moment. The arrival of these new-generation technologies enables a potentially decisive shift in the underlying balance of the sovereign public's and private actors' relative powers, competencies, and roles in the financial system. By making transacting faster, easier, cheaper, and instantly adjustable to individual parties' needs and preferences, new technology is empowering private actors to engage in virtually unconstrained financial speculation. Unless the public side proactively counters new technologies' potentially destabilizing systemic effects, it may soon find itself in an impossible position of having to back up an uncontrollable and unsustainably self-referential financial system. ${ }^{270}$

To be clear, the purpose of this Article is not to over-dramatize potential dangers, or to deny potential benefits, of fintech. Far from it. New technology opens a wide range of previously inconceivable possibilities for improving our shared financial lives and for creating fuller, more capacious forms of financial citizenship. ${ }^{271}$ At this relatively early stage, it would be premature to issue any definitive conclusions as to what fintech's ultimate impact on society is going to be, or what specific risks individual technologies are going to pose to financial stability. It is vitally important, however, to take an informed systemic view of the unfolding fintech "revolution" well before these risks materialize. Only by doing so can we begin harnessing the transformative power of fintech for our collective long-term benefit. This Article takes a critical first step toward that goal.

270. Such proactive public counter-action would have to be an exercise in applied institutional imagination on a deeper level, and in a far more encompassing manner, than what is typically involved in devising specific regulatory fixes to specific fintech-related problems. In practice, the latter often precedes the former, as regulatory agencies on the ground are usually the first to feel the immediate pressure to respond to specific market changes. Yet, to avoid the obvious pitfalls of a perennially fragmented piece-meal approach to fintech, it is critical to develop a normatively coherent and programmatic system-wide strategy of redefining the public-private balance of power in today's techdriven finance. What that strategy might look like, however, is the subject of a separate research project.

271. For a fascinating, and fascinatingly optimistic, account of these possibilities, see CASEY \& VIGNA, supra note 204. 